Illinois State University

ISU ReD: Research and eData

Theses and Dissertations

3-30-2018

\title{
Testing the Effects of Message Framing on Physical Activity Motivation in Active and Non-Active Adults
}

Derek James Hevel

Illinois State University, derekhevel@gmail.com

Follow this and additional works at: https://ir.library.illinoisstate.edu/etd

Part of the Kinesiology Commons

\section{Recommended Citation}

Hevel, Derek James, "Testing the Effects of Message Framing on Physical Activity Motivation in Active and Non-Active Adults" (2018). Theses and Dissertations. 862.

https://ir.library.illinoisstate.edu/etd/862

This Thesis is brought to you for free and open access by ISU ReD: Research and eData. It has been accepted for inclusion in Theses and Dissertations by an authorized administrator of ISU ReD: Research and eData. For more information, please contact ISUReD@ilstu.edu. 


\title{
TESTING THE EFFECTS OF MESSAGE FRAMING ON PHYSICAL ACTIVITY MOTIVATION IN ACTIVE AND NON-ACTIVE ADULTS
}

\author{
Derek J. Hevel
}

\section{Pages}

PURPOSE: Understanding how to best "sell" physical activity (PA) is a critical goal. This study investigated the effects of message framing on motivation to participate in a PA program, and tested whether the effectiveness of messages framed to promote either affective benefits, physical health benefits, or a combination of benefits varied based on one's current PA status. METHODS: Adult participants $(N=188)$ from a Midwestern university, who were recruited via email, completed an online survey assessing demographic information and current stage of change. They then viewed one of four randomly assigned promotional flyers for a PA program offered on campus. The flyers mentioned either the: (a) affective benefits of program participation (e.g., improved mood), (b) physical health benefits (e.g., improved fitness), (c) a combination of affective and physical health benefits, or (d) a control message noting some generic aspects of the program (e.g., clean facilities). After viewing the flyer, participants responded to a series of questions about the content of the flyers (manipulation checks) and their perceived behavioral control for participating in the program, followed by their interest in the program, intention to participate, the likelihood of participating, and whether they wanted to sign-up.

RESULTS: A series of 2 (PA status: active, non-active) x 4 (message: affective, physical health, combination, control) ANCOVAs found that, after accounting for perceived control, the 
effectiveness of the different promotional messages on intention and likelihood of participating varied based on the respondents' PA status. The major finding was messages promoting affective benefits led to significantly greater intention and likelihood of participation for those who are active. For the non-active participants, however, messages promoting physical health benefits led to significantly greater intention and likelihood of participation compared to other messaging types. No group or message differences were found with regard to interest in the program. Further, a chi-square analysis found no differences in participants' yes or no response to wanting to schedule a session in the program at that time.

CONCLUSION: Using message framing to sell PA may help increase intention and likelihood to participate. However, the type of message that effectively promotes PA appears to vary depending on the message receiver's current PA.

KEYWORDS: Exercise Psychology; Physical Activity Promotion; Intention 
TESTING THE EFFECTS OF MESSAGE FRAMING ON PHYSICAL ACTIVITY MOTIVATION IN ACTIVE AND NON-ACTIVE ADULTS

\author{
DEREK J. HEVEL
}

A Thesis Submitted in Partial Fulfillment of the Requirements for the Degree of

\title{
MASTER OF SCIENCE
}

School of Kinesiology and Recreation

\section{ILLINOIS STATE UNIVERSITY}


(C) 2018 Derek J. Hevel 
TESTING THE EFFECTS OF MESSAGE FRAMING ON PHYSICAL ACTIVITY MOTIVATION IN ACTIVE AND NON-ACTIVE ADULTS

\author{
DEREK J. HEVEL
}

COMMITTEE MEMBERS:

Anthony J. Amorose, Chair

Kristen M. Lagally

Anna Rinaldi-Miles

Scott Pierce 


\section{ACKNOWLEDGMENTS}

I would first like to express my gratitude for my committee members, Dr. Anthony Amorose, Dr. Kristen Lagally, Dr. Anna Rinaldi-Miles, and Dr. Scott Pierce, for their support, encouragement, and assistance. I would especially like to thank Dr. Anthony Amorose for his patience and guidance, for without his aid, this work would not have been possible. I would also like to thank my parents, Jim and Amy Hevel, for their everlasting love and support throughout my academic career. Lastly, Illinois State University has been home for the past six years. I have grown as a person and young scholar, thank you to all who fostered my education.

D. J. H. 


\section{CONTENTS}

Page

ACKNOWLEDGMENTS

$\begin{array}{ll}\text { CONTENTS } & \text { ii }\end{array}$

$\begin{array}{ll}\text { TABLES } & \text { iii }\end{array}$

FIGURES iv

CHAPTER I: TESTING THE EFFECTS OF MESSAGE FRAMING ON PHYSICAL

ACTIVITY MOTIVATION IN ACTIVE AND NON-ACTIVE ADULTS 1

$\begin{array}{ll}\text { Introduction } & 1\end{array}$

Affect and PA Behavior 2

Effects of Message Framing $\quad 4$

$\begin{array}{ll}\text { Methods } & 9\end{array}$

$\begin{array}{ll}\text { Participants } & 9\end{array}$

$\begin{array}{ll}\text { Procedure } & 10\end{array}$

$\begin{array}{ll}\text { Experimental Conditions } & 10\end{array}$

$\begin{array}{ll}\text { Measures } & 12\end{array}$

$\begin{array}{ll}\text { Data Analysis } & 15\end{array}$

$\begin{array}{ll}\text { Results } & 16\end{array}$

$\begin{array}{ll}\text { Preliminary Analysis } & 16\end{array}$

$\begin{array}{ll}\text { Main Analysis } & 19\end{array}$

$\begin{array}{ll}\text { Discussion } & 20\end{array}$

$\begin{array}{ll}\text { References } & 32\end{array}$

APPENDIX A: PHYSICAL ACTIVITY PROMOTION SURVEY 38 


\section{TABLES}

Table Page

1. Descriptive Statistics for Preliminary Analysis 26

2. Raw Mean Scores for Motivational Outcomes by Activity Status 27

3. Estimated Mean Scores for Motivational Outcomes 28 


\section{FIGURES}

Figure

1. Flyer Message by Condition $\quad 29$

2. Interest in the Physical Activity Program ANCOVA Results 30

3. Intention to Participate ANCOVA Results 30

4. Likelihood of Participation ANCOVA Results 31

5. Chi-Squared Analysis for Participants Indicating "Yes" to Sign-Up for the Program 31 


\section{CHAPTER I: TESTING THE EFFECTS OF MESSAGE FRAMING ON PHYSICAL}

ACTIVITY MOTIVATION IN ACTIVE AND NON-ACTIVE ADULTS

\section{Introduction}

Physical activity (PA) benefits overall health and well-being for participants, with increasing benefits from continued participation (Humphreys, McLeod, \& Ruseski, 2014). Unfortunately, recent data indicates that only $21 \%$ of adults in the United States meet the recommended dose of PA, and over $25 \%$ of adults engage in no leisure-time at all ("Facts about Physical Activity", 2014). Due to the current lack of PA, understanding mechanisms that will aid health and fitness professionals in promoting PA effectively is imperative (U.S. Department of Health and Human Services, 2000). One possibility is to explore PA branding; figuring out how to "sell" exercise effectively so people want to buy it. The overall goal of the study is to explore ways in which health care professionals $(\mathrm{HCP})$ can promote PA using effective message framing.

Health care professional's often "sell” PA to consumers based upon the physical health benefits. The American College of Sports Medicine (ACSM) encourages the use of the Exercise Is Medicine $^{\circledR}$ (EIM) program, which provides a pathway for HCPs to talk about their patient's PA (Sallis, 2015). EIM calls for HCPs to assess current PA at every visit, similar to other health markers like blood pressure, height, weight, etc. Thus, EIM includes PA as any other common vital sign. When tying PA to this brand, HCPs relate PA as a way to obtain positive physical health outcomes, like lowering blood pressure and losing weight. This is a logical sell for PA by the HCP because increased participation should increase overall physical health by lowering disease risk. However, a key question is whether "selling" exercise as a "vital sign" is appealing to the consumer? Recently, Segar, Guérin, Phillips, and Fortier (2016) have argued the answer 
might be "no". A better approach, according to these scholars, would be for HCPs to "sell" exercise as a way for people to get what they want now. For instance, HCPs could communicate to people that PA can lead to increases in positive affect and well-being (e.g., increased energy levels, decreased feelings of stress, enhanced mood, feelings of enjoyment). In other words, Segar and colleagues suggest framing the value of PA as a way to increase "vitality" instead of as a "vital sign" might be a better approach. While there is limited research testing this idea, increasing theoretical and empirical work exploring the role affect plays in PA behavior provides some support for the logic of their argument.

\section{Affect and PA Behavior}

Increasingly, scholars have explored the link between affective responses and PA behavior (Brand \& Ekkekakis, 2017; Ekkekakis, 2013). According to Ekkekakis and his colleagues (see Brand \& Ekkekakis, 2017; Ekkekakis, 2013; Ekkekakis \& Petruzzello, 2000), affect refers to the generalized feelings of pleasure versus displeasure a person experiences. From this perspective, affective responses include all the emotional states and moods contributing to the way in which a person feels good or bad. Thus, positive affect would include feelings such as enjoyment, pleasure, calmness, energy, and vitality, whereas negative affect would include feeling states such as boredom, anxiety, tension, and listlessness.

A variety of theoretical frameworks highlight the importance of affective responses on future PA behavior (e.g., Ryan \& Deci, 2017; Williams, 2008; Brand \& Ekkekakis, 2017). For example, Williams (2008) proposes an integrative model linking exercise intensity, affective responses, and exercise adherence. According to the model, exercise intensity indirectly influences acute affective responses through cognitive (e.g., perceived autonomy, anticipated affective responses) and interoceptive factors (e.g., ventilatory drive, lactate threshold). These 
acute affective responses then influence anticipated affective responses for future bouts of PA, and subsequently exercise adherence. Therefore, experiencing positive emotions while exercising is predicted to increase future exercise adherence.

Support for the importance of affect as a PA predictor has become increasingly clear in recent research, as well. For example, Williams et al. (2008) sought to examine how acute affect responses during an exercise bout (opposed to affective responses after the exercise was completed) influenced future PA participation. Participants performed a graded sub-maximal treadmill exercise while assessing their affective responses during the bout using the Feelings Scale (Rejeski et al., 1987). Participants then used the Physical Activity Recall scale (Blair et al., 1985; Sallis et al., 1985) to recall their physical activity for seven days at baseline, six, and twelve months after the exercise bout on the treadmill. Results indicated that participants displaying more positive affect during the exercise bout self-reported more minutes of PA at six months but not twelve months after the bout. Kwan and Brown (2010) also found that increases in positive affect during exercise were predictive of future exercise behavior, in this case three months later.

Kiviniemi, Voss-Humke, and Seifert (2007) found positive feelings about PA were also predictive of self-reported PA. Further, they reported affective responses mediated or partially mediated the effect of various cognitive variables typically used to predict PA (i.e., perceived benefits, barriers, attitudes, social norms, perceived control). Finally, other studies have reported that expecting exercise will make you feel good (i.e., anticipated affect) predicted exercise behavior (Dunton \& Vaughan, 2008; Gellert, Ziegelmann, \& Schwarzer, 2012) and intention (Helfer, Elhai, \& Geers, 2015). 
Support for the importance of affect also comes from research exploring the combined and relative effects of affective and instrumental (cognitive) attitudes on PA motivation. Lawton, Conner, and McEachan (2009) explored how affective and cognitive attitudes can predict health behaviors (e.g., exercise, PA) and the degree to which intention mediates these effects. Participants completed single-item measures for both affective (i.e., not enjoyable enjoyable) and cognitive (i.e., harmful - beneficial) attitudes, and then one month later reported their behavior and intentions. Results showed that affective attitudes for PA and exercise were stronger predictors of intention compared to cognitive attitudes. Another study by Lowe, Eves, and Carroll (2002) also explored how affective and instrumental attitudes effected exercise intention. Participants completed measures of exercise behavior, perceived behavioral control, subjective norm, intention, and affective and instrumental attitudes, sent via mail at baseline and six months later. After controlling for prior exercise behavior, affective beliefs were a predictor of self-reported exercise. Conversely, instrumental attitudes did not influence exercise behavior. In sum, theory and research supports that positive affect facilitates increased PA intention and continued participation. Therefore, promoting PA based upon these benefits or outcomes, as suggested by Segar et al. (2016), might be an effective way for HCPs to sell PA. Message framing might be one way to accomplish this sell.

\section{Effects of Message Framing}

The effects of message framing have received attention in health communication literature (Rothman \& Salovey, 1997; Updegraff \& Rothman, 2013). Message framing is a communication strategy used to promote the potential benefits of a behavior in the hopes that the message will encourage the recipient to adopt the desired behavior. Research in health communication has typically focused on the relative effectiveness of gain- versus loss-framed 
messaging. A gain-framed message highlights the benefits of adopting the behavior, whereas a loss-framed message emphasize the costs of not adopting the behavior (Updegraff \& Rothman, 2013). Rothman and Salovey (1997) propose in their prospect theory that gain-framed messages persuade individuals to engage in preventative behaviors (e.g., using sunscreen), while lossframed messages effectively urge people to engage in detection behaviors (e.g., performing a skin cancer self-examination). PA behavior is considered a preventative behavior because the action helps to mitigate the negative consequences of sedentary lifestyles, much like sunscreen prevents skin cancer, and research consistently supports the relative value of gain-framed messages in this context (see Latimer, Brawley, \& Bassett, 2008) Therefore, an effective behavior change strategy might consider emphasizing the benefits associated with adopting PA.

The majority of research on message framing and PA has focused on comparing gainversus loss-framed messages; however, scholars have begun to examine other aspects of message framing such as the effectiveness of affective versus instrumental messaging. Affective messaging highlights emotional benefits like better mood or increased energy levels, while instrumental messaging promotes PA as a way to gain benefits like increasing cardiovascular fitness or losing weight. Conner, Rhodes, Morris, McEachan, and Lawton (2011) sought to examine the impact of messaging (e.g., participants received written statements, which in some conditions were also accompanied by pictures) on self-reported exercise within two studies. Study 1 compared affective messages (e.g., regular PA has been shown to reduce anxiety) to instrumental (e.g., regular PA has been shown to reduce the risks of developing colon and breast cancer) and no-message control, and found that the greatest change in exercise behavior over a three-week period occurred for those receiving the affective messages. Similar results were found in Study 2. However, they also found that the significant increase in PA resulting from 
receiving an affective message was only consistent for those low in need for control and for those high in need for affect. Overall, both of these studies suggest that affective messaging, more so than instrumental messaging, can positively change affective attitudes and exercise behavior.

Sirriyeh, Lawton, and Ward (2015) examined the influence of message framing effects on adolescents' PA levels. Participants $(N=120)$ completed the International Physical Activity Questionnaire (IPAQ; Craig, et al., 2003) to assess PA behavior and were divided into four experimental conditions. The conditions manipulated affective benefits (i.e., enjoyable/unenjoyable), instrumental benefits (i.e., beneficial/harmful), a combination of affective and instrumental benefits, and a control condition using text messages. For a 14-day period, the participants received one SMS text message consistent with their group assignment per day. At the end of the two-week intervention, participants again completed the IPAQ. Results revealed a significant interaction between the text message conditions and level of PA at the beginning of the study. Specifically, they found that inactive participants who received affective messages increased their PA levels significantly more than the instrumental group and the combined group.

The results of the studies by Conner et al. (2011) and Sirriyeh and colleagues (2015) provide some support for the call by Segar and colleagues (2016) to "sell" PA as a way to promote "vitality" (i.e., promoting the affective benefits) versus the conventional "vital sign" (i.e., promoting the physical health or instrumental benefits). Nevertheless, there are questions that still need to be addressed. For instance, what are the possibilities of promoting both affective and physical health benefits simultaneously? 
If current research supports affective messaging as a new way to "sell" PA and HPC's are currently using instrumental messaging to "sell" PA, why not combine them both? Current research suggests that this might not be as effective as one might think. Zhang, Fishbach, and Kruglanski (2007) introduced the dilution model focusing on this question. This model proposes that when two goals add to a single mean, the strength of the association of either goal with the mean is diminished. For example, providing someone with information that PA can help them to lose weight might be compelling. However, if the message also provides information about the ability of PA to reduce their blood pressure, the person is likely to weakly associate the value of PA as a modality to lose weight or lower blood pressure. In other words, the addition of the second benefit (i.e., goal) weakens the association with the other benefit of the behavior to the desired outcome (i.e., mean). Zhang and colleagues (2007) provided some support for the dilution effect in a series of studies. For example, participants in Study 1 read short essays about a how a single mean (e.g., aerobic exercise) might satisfy either one goal (e.g., protection from heart disease) or two distinct goals (e.g., protection from heart disease and maintain healthy bones). When more than one goal was added to a single mean (e.g., aerobic exercise), it weakened the overall instrumentality of the single mean.

Based on the dilution effect demonstrated by Zhang and colleagues (2007), adding both affective and instrumental content to a message as a way to promote PA might not be as effective as just promoting one benefit (or type of benefit). Some support for this idea can also be seen in the results of Sirriyeh and colleagues (2015). Analysis of the results indicated the combined condition (where messages included a combination of affective and instrumental benefits) was not as effective at promoting PA compared to the affective alone message condition. Further, there were no differences between the instrumental, combined, and control conditions in their 
effect on PA. These results and the dilution model suggest that there might be diminishing returns from adding more goals, yet the relative lack of research on the issue within the PA domain makes this question worth exploring further.

Another question needing to be addressed is whether affective and/or instrumental messages will be more or less effective depending upon certain characteristics of the recipient. Message framing research has explored a host of variables that moderate the message's function on various health behaviors (see Covey, 2014; Rothman et al., 2008; Updegraff \& Rothman, 2013). Age (e.g., Berry \& Carson, 2010; Kin-Kit, Sheung-Tak, \& Fung, 2014), gender (e.g., KinKit et al., 2014; van 't Riet, Ruiter, Werrij, \& de Vries, 2010), dispositional needs for affect and cognition (Conner et al., 2011), source credibility (Arora, Stoner \& Arora, 2006; Jones, Sinclair, \& Courneya, 2003), temporal salience (Morris et al., 2016), and regulatory fit (Latimer et al., 2008; Pfeffer, 2013) are examples of moderating variables that have been explored in the research on messaging and PA. Of particular interest in this study is current PA behavior as a potential moderating variable. A few studies (e.g., Berry \& Carson, 2010; de Bruijn, Out, \& Rhodes, 2014; Sirriyeh et al., 2015; van 't Riet et al., 2010) have specifically tested whether PA status moderates the effect of different messages, and the results are somewhat inconsistent. For example, van 't Riet and colleagues (2010) found no differences in the effect of gain- vs lossframed messages on intention and PA behavior 3 months later between those who were or were not already meeting recommended PA guidelines. Berry and Carson (2010), de Bruijn et al. (2014) and Sirriyeh et al. (2015), on the other hand, found PA status moderated the effectiveness of messages. While the specific effects of the moderation varied, the results point to the possibility that active and non-active people may respond differently to messages. 
The goal of the current study is to understand the effect of message framing on PA motivation. Specifically, the purpose was to test the relative effectiveness of messages framed to promote either affective benefits, physical health benefits, or a combination on PA motivation. The study also investigated whether the effectiveness of the different messages varied based on one's current PA status. It was hypothesized that affective messages will be more effective at promoting interest, intention, and likelihood to participate in a PA program compared to physical health messages, a combination of affective and physical health, or a control message. Additionally, based on the dilution model (Zhang et al., 2007), it was hypothesized that the combination condition will be no more effective than either the vitality or vital sign condition. Active and non-active participants might differ in their motivational outcomes. However, given the lack of consistency in the research involving activity status and the effects of message framing on motivational outcomes (e.g., Berry \& Carson, 2010; de Bruijn et al., 2014; Sirriyeh et al., 2015), no specific hypothesis was made.

\section{Methods}

\section{Participants}

Participants $(N=188)$ completed an online survey sent via email to the community of a Midwestern University. Of this group, 18 were eliminated based on their response to the manipulation check questions, leaving 170 people in the final sample. These were predominately female $(70.60 \%)$ with a mean age of 46.07 years $(S D=14.01)$ and a range of 21 to 74 years. Most participants identified themselves as Caucasian/White (90.60\%), with the remaining identifying as black or African American (2.90\%), Asian (1.80\%), Hispanic/Latino (4.10\%), or Other $(0.60 \%)$. Finally, most participants $(65.30 \%)$ currently considered themselves regularly active. 


\section{Procedure}

The university Institutional Review Board at Illinois State University approved all study procedures. An anonymous online survey was sent via email to university community members who had agreed previously to receive solicitations for research projects. The survey began by explaining the general purpose of the study, that participating was voluntary, and completing the survey constituted informed consent.

The survey was broken into sections. First, participants responded to basic demographic questions, current PA status, and their attitudes toward PA in general. Next, the survey included a promotional flyer for a PA program offered on campus. The content of the promotional flyer served as the experimental manipulation. After viewing the randomly assigned promotional flyer, the participants responded to a series of manipulation checks. These were followed by assessments of their attitudes about the program described in the promotional flyer, their perceived control for participating, and their motivation to participate in the program.

\section{Experimental Conditions}

Participants were randomly assigned to receive one of four flyers promoting a PA program on campus. Although the program was fictitious, the respondents were led to believe the program was real. All flyers indicated that the program had been designed by faculty within the School of Kinesiology and Recreation (KNR) with the latest knowledge and research on exercise programming. However, the flyers varied in the reported benefits of participating in the program; highlighting either vitality messages (e.g., better mood), vital sign messages (e.g., improved cardiovascular fitness), a combination of the two messages (e.g., better mood and improved cardiovascular fitness), or a control message (e.g., nice facilities). Across all four conditions, the 
order in which the specific benefits were presented was counterbalanced to minimize the potential of any order effects.

Vitality Condition. The vitality condition $(n=48)$ highlighted the affective benefits of the PA program (see Figure 1 - Panel A). The flyer cited previous participants of the program stating it helped increase their mood or increased their energy level. The program staff quote highlighted research has shown that PA can increase in overall feelings of well-being.

Vital Signs Condition. The vital signs condition $(n=42)$ highlighted the physical health benefits received from the PA program (see Figure 1 - Panel B). Within this flyer, previous participants cited the program helped increase their cardiovascular fitness and helped control their weight. The program staff provided a quote citing research showing PA increases overall physical health.

Combination Condition. The combination condition $(n=43)$ promoted both affective and physical health benefits of the fictions PA program (see Figure 1 - Panel C). Previous program participants highlighted a vitality benefit (e.g., increased their energy) and a vital sign benefit (e.g., helped control weight). The program staff shared that research indicates physical activity helps improve overall physical health and increase overall feelings of well-being.

Control Condition. The control condition $(n=37)$ highlighted parts of the program unrelated to the health or affective benefits obtained from the PA program (see Figure 1 - Panel D). A previous participant of the program said the program had clean facilities while the other program participant said the program ran smoothly. The program staff cited that having the program on campus was great. 


\section{Measures}

Pre-Manipulation Measures. The following measures used in this study were presented before the flyers describing the PA program were introduced.

Demographics. Participants were asked to report their age, gender, and race/ethnicity. Stage of Change. The short-form of the Exercise: Stages of Change questionnaire was used to determine current PA status (Exercise: Stage of Change (Short Form), n.d.). The instructions for the measure are as follows: "Regular exercise is planned physical activity (e.g., brisk walking, aerobics, jogging, bicycling, swimming, rowing, etc.) performed to increase physical fitness. Such activity should be performed 3 to 5 times per week for 20-60 minutes per session. Exercise does not have to be painful to be effective but should be done at a level that increases your breathing rate and causes you to break a sweat. Do you exercise according to the criteria?" There are five possible response items to choose from, the first acknowledges that they are currently physically active and have been for at least 6 months (i.e., maintenance stage). In the next option, the participant acknowledges they are currently physically active but doing so for less than 6 months (i.e., action stage). In the third option, participants are not regularly physically active but intend on becoming active in the next 30 days (i.e., preparation stage). The fourth option, the participant acknowledges they are not currently physically active but intend on becoming active within the next 6 months (i.e., contemplation stage). Finally, in the last option participants agree that they are not physically active and do not intend on becoming physically active for the next 6 months (i.e., precontemplation stage). Participants in the maintenance and action stages were grouped and labeled as active whereas participants in the preparation, contemplation, and precontemplation stages were grouped and labeled as non-active. 
Attitudes - General PA. Exercise attitudes were measured with a 7-point bipolar adjective scale created by Rhodes and Courneya (2005). Affective attitudes were assessed with three items (enjoyable - unenjoyable, interesting - boring, relaxing - stressful). Three items assessed instrumental attitudes (e.g., useful - useless, wise - foolish, beneficial - harmful). Higher scores on the measure indicated the respondent endorsed the more positive adjective. Cronbach's alpha coefficients indicated that these scales all had acceptable internal consistency in the final sample ( $\alpha=.86$ for affective attitude, $\alpha=.92$ for instrumental attitude, $\alpha=.87$ for general attitude).

Post-Manipulation Measures. The following measures used in this study were included in the survey after the participants were provided with the randomly assigned promotional flyer.

Manipulation Check Questions. Participants were asked to respond to a series of questions about the promotional flyer they viewed. These questions were used to ensure the participants retained the relevant information about the PA program, and thus served as manipulation checks. Using a 5-point scale ( $1=$ definitely false, $5=$ definitely true), participants indicated whether the KNR physical activity program led to: (a) psychological/emotional benefits (e.g., better mood, increased energy), (b) physical health benefits (e.g., controlled weight, increased cardiovascular fitness), (c) a combination of both psychological/emotional and health benefits, and (d) occurs in a newly updated facility. They were also given the option to respond with unsure/do not know. These four questions corresponded to four different promotional flyer conditions. The manipulation checks were used to ensure participants comprehended the flyer message. Therefore, if a participant responded "probably false", "definitely false" or "unsure/do not know" to the manipulation check corresponding to their flyer message condition, they were removed from the study. For example, if a participant in the 
vitality condition responded "probably false" to whether or not the program "led to psychological/emotional benefits for former participants (e.g., better mood, increased energy)" they were removed from the study because the vitality condition stated the PA program led to those listed benefits.

Perceived Control. A three-item measure assessed behavioral control specific to the KNR PA program. The measure of perceived behavioral control was adapted from Rhodes and Courneya (2005) and Parrott, Tennant, Olejnik, and Poudevigne (2008). First, participants responded to "How confident are you that you could participate in the KNR physical activity program if you wanted to do so?"; measured on a 7-point scale ranging from 1 (very unconfident) to 7 (very confident). Second, participants responded to "How much personal control do you feel you have over participating in the KNR physical activity program?"; measured on a 7-point scale from 1 (very little control) to 7 (complete control). The third question asked: "Participating in the KNR physical activity program is completely up to me."; measured on a 7-point scale from 1 (strongly disagree) to 7 (strongly agree). An average of the responses to these questions were used to reflect the respondents' perception of control to participate in the PA program, with higher score reflecting greater perceived control. Cronbach's alpha coefficient indicated that this scale had acceptable internal consistency in the final sample $(\alpha=.77)$.

Motivation to Participate. Four single-item questions assessed motivation to participate in the PA program. Specifically, the indicators of motivation explored the participants' interest, intention, likelihood of participation, and whether they wanted to sign-up. First, participants responded to: "How interested are you in learning more about the KNR physical activity program?", answering on a 7-point scale ranging from 1 (not at all interested) to 7 (very 
interested). Intention was assessed by "Do you intend on signing up for the KNR physical activity program this school year?", using a 7-point scale ranging from 1 (do not intend to sign up at all) to 7 (strongly intend to sign up). "How likely is it that you will participate in the KNR physical activity program this school year?" measured likelihood of participation and was assessed by a 7-point scale ranging from 1 (extremely unlikely) to 7 (extremely likely). The fourth question prompted: "If you would like to go ahead and schedule an initial session in the KNR physical activity program, click the option labeled 'Yes'. If not, please click 'No'". The response options for this question were: "Yes - I would like to sign up for an initial session (Clicking this link will allow you to access the KNR physical activity program scheduling calendar at the conclusion of the survey)." or "No - I am not interested in scheduling a session.".

\section{Data Analysis}

A series of preliminary analyses were conducted to establish that the manipulation of the PA program benefits reported in the different flyers and that the randomization of participants to condition were effective. First, one-way ANOVAs were used to test for differences across the flyer conditions in the manipulation check questions. Next, ANOVAs and Chi-Square analyses were used to determine if there were any differences in general attitudes about PA, age, gender, and activity status across the flyer conditions.

The main analyses included a series of $2 \times 4$ (activity status: active vs. non-active $\mathrm{x}$ message condition: vitality, vital sign, combination, control) ANCOVAs, with perceptions of control serving as a covariate. Separate analyses were conducted on each of the three continuous motivation indicators (interest, intention, likelihood of participation). Post-hoc analyses were used to probe significant interactions and main effects, and effect sizes for any significant effects were reported as $\eta^{2}$. Finally, a chi-square analysis was used to determine whether there were 
differences in actually agreeing to sign up for an initial session of the PA program between the various message conditions. An alpha level of 0.05 was used for all analyses to evaluate significance.

\section{Results}

\section{Preliminary Analysis}

Manipulation Checks. Participants completed manipulation checks after viewing the flyer message. Eighteen people were removed from the original sample size because they indicated either "probably false", "definitely false", or "unsure/do not know" to the statement listed on their flyer. No participants were removed from the vitality condition, six participants were removed from the vital signs condition, one participant was removed from the combination condition, and eleven participants were removed from the control condition.

Table 1 identifies means and standard deviation scores for the manipulation check questions by condition for the final sample $(N=170)$. A separate ANOVA was conducted for each manipulation check question to determine if the responses varied by flyer condition. Results showed that there were significant differences on the question about vitality benefits, $F(3,157)$ $=9.27, p<.01, \eta^{2}=.15$. Student-Newman-Keuls $(\mathrm{SNK})$ post hoc tests revealed significant differences between vitality and combination condition compared to the control and vital sign condition. Participants who were exposed to a flyer where at least one person mentioned an affective-based benefit of the program were more likely to agree that increased vitality was a benefit of the program. Significant differences by flyer condition were also found for the vital sign benefits question, $F(3,156)=40.82, p<.01, \eta^{2}=.44$. A SNK post hoc test found differences between the vital sign flyer and combination flyer condition compared to the control and vitality conditions. Participants who were exposed to a flyer where at least one person 
mentioned a vital sign (i.e., physical health) benefit of the program were more likely to agree that increased physical health was a benefit of the program. The differences across flyer condition on the combination of benefits was also significant $F(3,156)=2.64, p<.01, \eta^{2}=.10$. A SNK post hoc analysis indicated that those is the control flyer condition reported significantly lower scores on this question relative to the other flyer conditions which were not significantly different from each other. Thus, those participants in three experimental groups who were exposed to at least one mention of an affective or physical health benefit were more likely to agree that these types of benefits would exist compared to the control group participants who were told nothing about these types of benefits. Finally, no significant differences across the flyer conditions were found for the question asking about the program occurring in a new facility, which was one of the main comments made on the control flyer condition, $F(3,113)=1.88, p=.05, \eta^{2}=.07$.

Randomization Success. Descriptive statistics on general attitude, age, activity status and gender by flyer condition are also included in Table 1. Separate ANOVAs were conducted for attitude, (i.e., general, affective, and instrumental attitudes) and age to determine if there were any differences in these variables across the flyer conditions. Results indicated non-significant differences in general attitude, $F(3,166)=.47, p=.70, \eta^{2}=.01$, affective attitude, $F(3,166)=$ $.59, p=.62, \eta^{2}=.01$, instrumental attitudes, $F(3,166)=.258, p=.86, \eta^{2}=.01$, and age, $F(3$, 166) $=.73, p=.53, \eta^{2}=.01$.

A chi-squared analysis was performed and revealed no relationship between message conditions and activity status, $X^{2}(3, N=170)=1.58, p=0.67$. Additionally, another chisquared analysis was performed and revealed no relationship between message conditions and gender, $X^{2}(3, N=170)=5.88, p=0.12$. Since no significant differences between the groups 
emerged in general attitude, vitality attitude, vital signs attitude, or age, the randomization between conditions was deemed successful.

Descriptive Statistics for the Motivational Outcomes. The descriptive statistics on the motivational outcomes are presented in Table 2 . When considering the total sample of participants, interest was higher than the midpoint of the scale, whereas intention and likelihood of participation were around the midpoint, of the 1 to 7 scale. These suggest that overall the sample reported moderate to high motivation for the KNR program. The percentage of people interesting in signing up for the program, however, was relatively low with only $35.90 \%$ saying yes.

The descriptive data also indicates that those who are currently physically active report higher motivation across all four measures than those who are non-active. The data included in Table 2 also suggests that those in the vitality condition reported higher mean scores for interest, intention, and likelihood of participation than other conditions. For the sign-up motivational outcome, however, those in the vital signs condition indicate a higher percentage of participants wanting to sign up for the program. Consistently throughout the motivators, the control group indicated the least amount of motivation.

Bivariate correlations for the motivational outcomes were computed to better understand their relationship. Intention and likelihood of participation show a strong positive correlation $r(168)=.91, p<.01$. Interest and intention $r(168)=.67, p<.01$ and interest and likelihood of participation $r(168)=.65, p<.01$ showed moderate positive correlations between the variables. Sign-up ("yes" = 1 and "no" =0) and interest $r(168)=.48, p<.01$, sign-up and intention $r(168)$ $=.48, p<.01$, and sign-up and likelihood of participation $r(168)=.49, p<.01$ revealed moderate positive correlations. 


\section{Main Analysis}

To test if the differences in interest, intention, and likelihood of participation significantly varied by flyer condition and/or activity status, a series of 2 x 4 (activity status: active vs. nonactive $\mathrm{x}$ message condition: vitality, vital signs, combination, and control) ANCOVAs controlling for perceived control was conducted. The estimated marginal means for these analyses can be found in Table 3 and the patterns are illustrated in Figures 2-4. In the analysis of the interest variable, the perceived control covariate yielded a non-significant result, $F(1,161)=$ $2.59, p=.11, \eta^{2}=.02$. Main effects for the message, $F(3,161)=2.12, p=.10, \eta^{2}=.04$, and activity status, $F(1,161)=.00, p=.99, \eta^{2}=.00$, were non-significant. The interaction between the message and activity status was non-significant as well, $F(3,161)=.97, p=.41, \eta^{2}=.02$.

In the analysis of intention to participate in the program, the perceived control covariate was significant, $F(1,161)=6.63, p=.01, \eta^{2}=.04$. The main effects of message, $F(3,161)=.83$, $p=.48, \eta^{2}=.02$, and activity status, $F(1,161)=.70, p=.41, \eta^{2}<.01$, were non-significant. The interaction between message and activity status, however, was significant, $F(3,161)=4.50, p<$ $.05, \eta^{2}=.08$. As seen in Table 3 and illustrated in Figure 3 for those who are active, intention to participate was highest after receiving a vitality message. Conversely, non-active participants were more likely to intend to participate after receiving a vital sign message.

In the likelihood of participation analysis, the covariate of perceived control was significant, $F(1,161)=7.01, p<.01, \eta^{2}=.04$. The main effects of message, $F(3,161)=.65, p=$ $.59, \eta^{2}=.01$, and activity status, $F(1,161)=.41, p=.52, \eta^{2}<.01$, were non-significant. However, the interaction between message and activity status was significant, $F(3,161)=3.61$, $p<.05, \eta^{2}=.06$. Figure 4 shows the relationship of the interaction by condition and physical activity status. Likelihood of participation was highest in the vitality condition for those who are 
more active. For those who are non-active, the vital sign condition scored higher than those who received the vitality message.

A chi-squared analysis was performed and revealed no relationship between activity status and frequency of signing-up for the PA program $X^{2}(3, N=170)=1.03, p=0.79$. Thus, wanting to sign up for the program was not significantly different across groups (see Figure 5).

\section{Discussion}

The purpose of the study was to understand the effects of message framing on PA motivation, and to test whether the effectiveness of different messages was dependent on PA status. The main hypothesis proposed that affective messaging (compared to physical health benefits, combined benefits, or the control message) would be a better predictor of motivation in terms of interest, intention, likelihood of participation, and whether or not the message recipient would like to sign up for a program. Further, PA status was expected to potentially alter the way the messages influenced motivation; however, no specific pattern was predicted given the limited and mixed results of previous research.

Results of the study provided partial support for the hypothesis in that the type of messages led to variations in two of the four indicators of motivation. Further, activity status influenced which messages were more or less effective. Consistent with the hypotheses, the affective messages yielded higher motivation scores for intention and likelihood of participation when participants were active. The positive responses to the vitality messaging for this group is

consistent with Segar and colleagues (2016) who purports selling PA through vitality messaging might increase participation.

The results for the non-active participants, on the other hand, were unexpected. Specifically, non-active participants found vital sign messaging as more motivating in terms of 
intention and likelihood to participate. The current findings are different from previous research where non-active participants rated vitality messaging as more motivating (Sirriyeh et al., 2015; Conner et al., 2011).

There are a few potential explanations for the lack of support found for the hypothesis with the non-active participants. First, both the sample and design of the current study differs from some of the previous research. For example, Sirriyeh and colleagues (2015) included adolescents from ages 16 to 19 in their sample, whereas the current study includes mostly middle-aged adults. In addition, the design of the Sirriyeh and colleagues (2015) study utilized text messaging once a day for fourteen days consecutively. The current study presented a promotional flyer containing the message on one occasion and then called for participants to indicate their interest, intention, likelihood of participation, and whether or not they wanted to sign-up for the program. Perhaps the variations in the methods contributed to the different pattern of results.

A second possibility is that non-active participants might think programs focusing on physical health benefits are better because that is the current "sell". If the participant views the program as being in line with the goals from $\mathrm{HCP}$, which is the most prevalent message promoted, then the physical health benefits might appear motivating because that is what they have consistently been told should be the goal of PA - to improve physical health. On the other hand, those who are already active, and have likely experienced many of the affective benefits while engaging in PA, might be more motivated for a program that suggests it focused on these types of benefits.

Future research is needed to explore the underlying mechanisms influencing how active and non-active people respond to different types of messages. For instance, do these groups of 
people vary in their desire and/or ability to process different messages? Berry and colleagues (2010) found non-exercisers might not find PA messages as personally relevant, and therefore they may not process the messages in the same way. Further, Segar and colleagues (2016) note that non-active individuals tend to have less anticipated positive affect for PA. Perhaps messages promoting affective benefits are less believable or relevant, and therefore these individuals would be less like to process the information contained in the message. It would be interesting to see if repeated messages selling the positive affective benefits (i.e., vitality benefits) of PA are required to entice non-active participants to become more active like was found in Sirriyeh et al. (2015). The limited exposure to vitality messaging may be considered a limitation of the study then, as perhaps it takes cultivation over a longer period to change the way non-active individuals view PA.

Another interesting finding that emerged from the study involved the combination condition. If vitality and vital sign messaging offers motivational benefits for PA, why not combine both types of messaging? Consistent with previous research (Zhang et al., 2007; Sirriyeh et al., 2015), the current study hypothesized that combining the two message types together would offer no motivational advantage. When adding multiple goals (e.g., affective benefits and physical health benefits) to a single mean (e.g., PA) the strength of the association between the goals and the mean decreases. In the current study, when vitality and vital sign messages were combined, there was no observed increase in motivation or a difference between the other messaging conditions. It seems that adding both vitality and vital sign messages together is not the message framing solution to increased PA participation.

While the results indicated that different messages affected PA motivation, it is important to note that this was only true for two of the four indicators of motivation. Conceptually, all the 
indicators included are common in the literature of PA motivation, and thus there was no reason to expect a different pattern of results. The reason for the lack of effect found with interest and signing up for the program remain unclear. Future studies should replicate the study to determine if the pattern of results was unique to this sample. Replicating and extending the study to include other ways to assess these constructs might help to determine if measurement issues (e.g., use of single item indictors) affected the results.

Any future research should also be sure include a variety of behavioral indicators of motivation. The previous studies on the effectiveness of affective and instrumental messaging have focused on self-reported PA behavior as the main motivational variable. For example, Conner et al. (2011) used the Godin Leisure Time Exercise Questionnaire (GLTEQ; Godin \& Shepard, 1985) and Sirriyeh et al. (2015) used the International Physical Activity Questionnaire (IPAQ; Craig et al., 2003) to assess PA behavior. These methods make sense given the purpose was to track behavior change over time. The question about wanting to sign up to schedule an initial session in the PA program being promoted in this study was included in as a behavioral indicator of motivation, insomuch as this question referred to a specific action the participants were willing to take at that moment. This was consistent with the design of the current study, where the focus was on recruiting participants into a specific PA program. Despite the lack of effect found in this study, future studies should continue to explore whether the effect of message framing is distinct across different aspects of motivated behavior (self-report and objective assessment), as change in actual PA behavior is the true goal of any PA promotion.

Another important avenue of future research involves exploring potential moderating factors, such as source credibility, temporal salience, and regulatory fit as important factors in understanding the differences between vitality and vital sign messaging. Previous research found 
various factors moderate the effects of message framing (see Covey, 2014; Rothman et al., 2008; Updegraff \& Rothman, 2013). Results from studies such as these could help determine how HCPs might need to "sell" PA differently depending on various characteristics of messages and/or message recipients.

A number of limitations of the current study are noteworthy. First, the representation of the sample was limited by the fact that the participants included predominantly active, female, and Caucasian/White participants. Message framing effects on PA might differ with other populations (e.g., populations outside of a university setting). Another limitation of the study was the hypothetical and vague nature of the flyer message. The flyers were purposefully vague and offered as little information as possible to minimize the risk of a particular PA modality to be more or less unsavory or desirable. However, this vague and hypothetical program could have had an undesired effect and left participants with uncertainties about the program and subsequently altered the results. The single presentation of the message is also a limitation, as this limited exposure might not elicit a great deal of information processing on the part of those who viewed the flyers. Finally, it is possible that the use of previous participants and program staff to "sell" the benefits of the PA program in the flyers was not sufficiently persuasive.

In summary, the findings of the study indicate that message framing can alter aspects of PA motivation, although the effects vary by PA status. HCP's should consider their patient's PA status when selling PA. Results from the current study suggest selling the vital sign benefits (i.e., physical health benefits) to non-active people leads to greater intention and likelihood of participation in a specific PA program. Additionally, for those who are active, HCP's should sell PA based upon the vitality benefits (i.e., affective benefits) as those benefits led to greater intention and likelihood of participation. Programs that sell PA based upon the vital sign benefits 
(e.g., EIM) may be effective for non-active individuals but be less effective for active individuals. HCP's and intervention programs should carefully consider their target population when choosing their PA sell and subsequent message. 


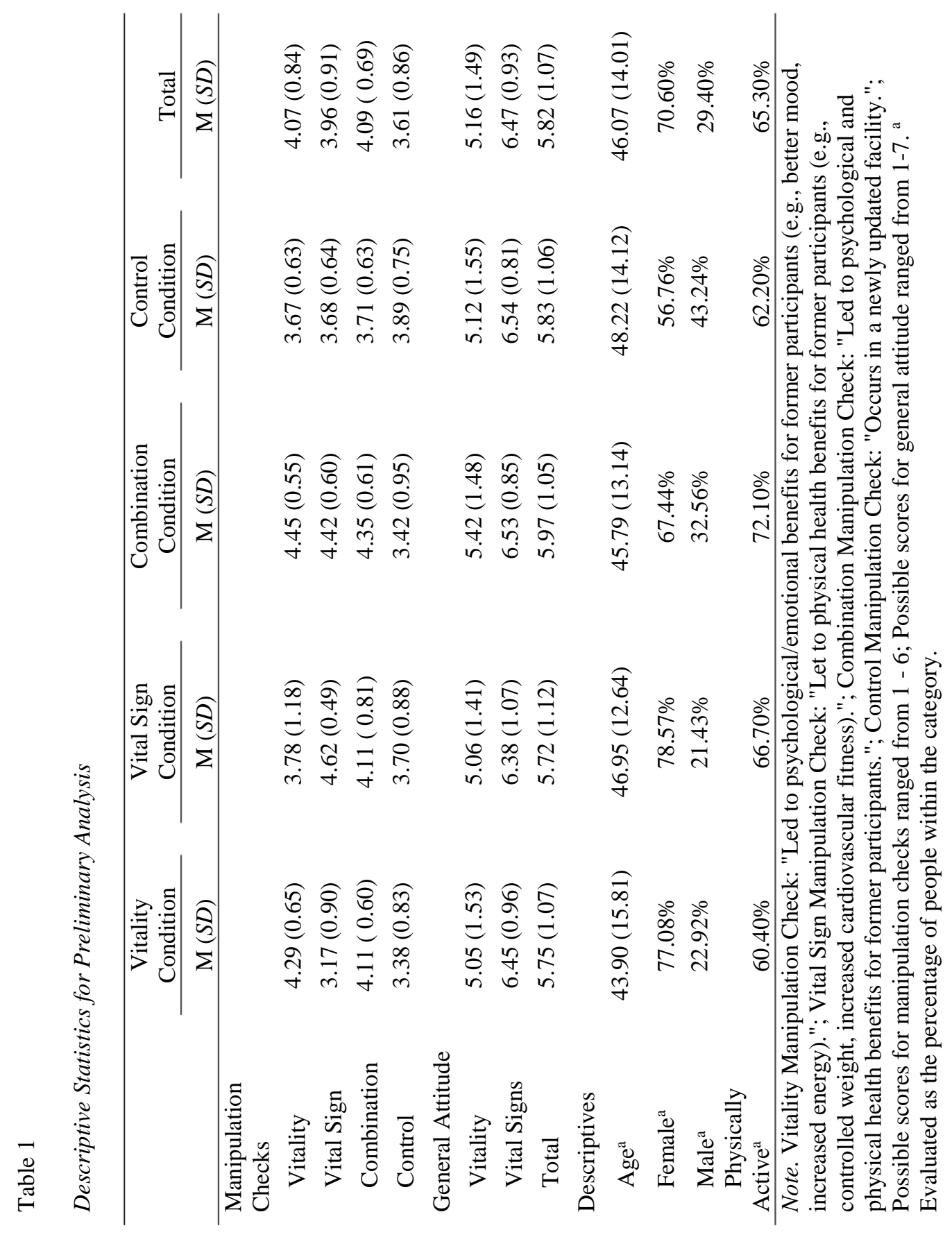


Table 2

Raw Mean Scores for Motivational Outcomes by Activity Status

\begin{tabular}{|c|c|c|c|c|c|}
\hline & $\begin{array}{l}\text { Vitality } \\
(n=48)\end{array}$ & $\begin{array}{l}\text { Vital Sign } \\
(n=42)\end{array}$ & $\begin{array}{c}\text { Combination } \\
\quad(n=43)\end{array}$ & $\begin{array}{l}\text { Control } \\
(n=37)\end{array}$ & $\begin{array}{c}\text { Total by } \\
\text { Activity } \\
\text { Status }\end{array}$ \\
\hline Motivational Outcome & $M(S D)$ & $M(S D)$ & $M(S D)$ & $M(S D)$ & $M(S D)$ \\
\hline \multicolumn{6}{|l|}{ Interest $^{\mathrm{a}}$} \\
\hline Active $(n=111)$ & $5.62(1.05)$ & $4.82(1.63)$ & $5.06(1.90)$ & $4.30(2.10)$ & $4.99(1.74)$ \\
\hline Non-Active $(n=59)$ & $4.95(1.47)$ & $5.36(1.87)$ & $4.83(1.53)$ & $4.36(1.55)$ & $4.88(1.60)$ \\
\hline Total By Condition & $5.35(1.26)$ & $5.00(1.71)$ & $5.00(1.79)$ & $4.32(1.89)$ & $4.95(1.69)$ \\
\hline \multicolumn{6}{|l|}{ Intention a } \\
\hline Active $(n=111)$ & $4.62(1.37)$ & $3.32(1.36)$ & $3.45(1.90)$ & $3.09(1.93)$ & $3.65(1.74)$ \\
\hline Non-Active $(n=59)$ & $2.79(1.23)$ & $3.86(1.51)$ & $3.25(1.55)$ & $3.21(1.72)$ & $3.24(1.50)$ \\
\hline Total By Condition & $3.90(1.59)$ & $3.50(1.42)$ & $3.40(1.79)$ & $3.14(1.83)$ & $3.51(1.67)$ \\
\hline \multicolumn{6}{|c|}{ Likelihood of Participation a } \\
\hline Active $(n=111)$ & $4.41(1.15)$ & $3.32(1.42)$ & $3.48(1.90)$ & $3.00(1.91)$ & $3.59(1.68)$ \\
\hline Non-Active $(n=59)$ & $2.79(1.55)$ & $3.79(1.63)$ & $3.25(1.55)$ & $3.21(1.58)$ & $3.22(1.58)$ \\
\hline Total By Condition & $3.77(1.53)$ & $3.48(1.49)$ & $3.42(1.79)$ & 3.08 (1.77) & $3.46(1.65)$ \\
\hline \multicolumn{6}{|l|}{ Yes Sign-up $^{\text {b }}$} \\
\hline Active $(n=111)$ & $37.90 \%$ & $39.30 \%$ & $41.90 \%$ & $39.10 \%$ & $39.60 \%$ \\
\hline Non-Active $(n=59)$ & $31.60 \%$ & $42.90 \%$ & $25.00 \%$ & $14.30 \%$ & $28.80 \%$ \\
\hline Total By Condition & $35.40 \%$ & $40.50 \%$ & $37.20 \%$ & $29.70 \%$ & $35.90 \%$ \\
\hline
\end{tabular}




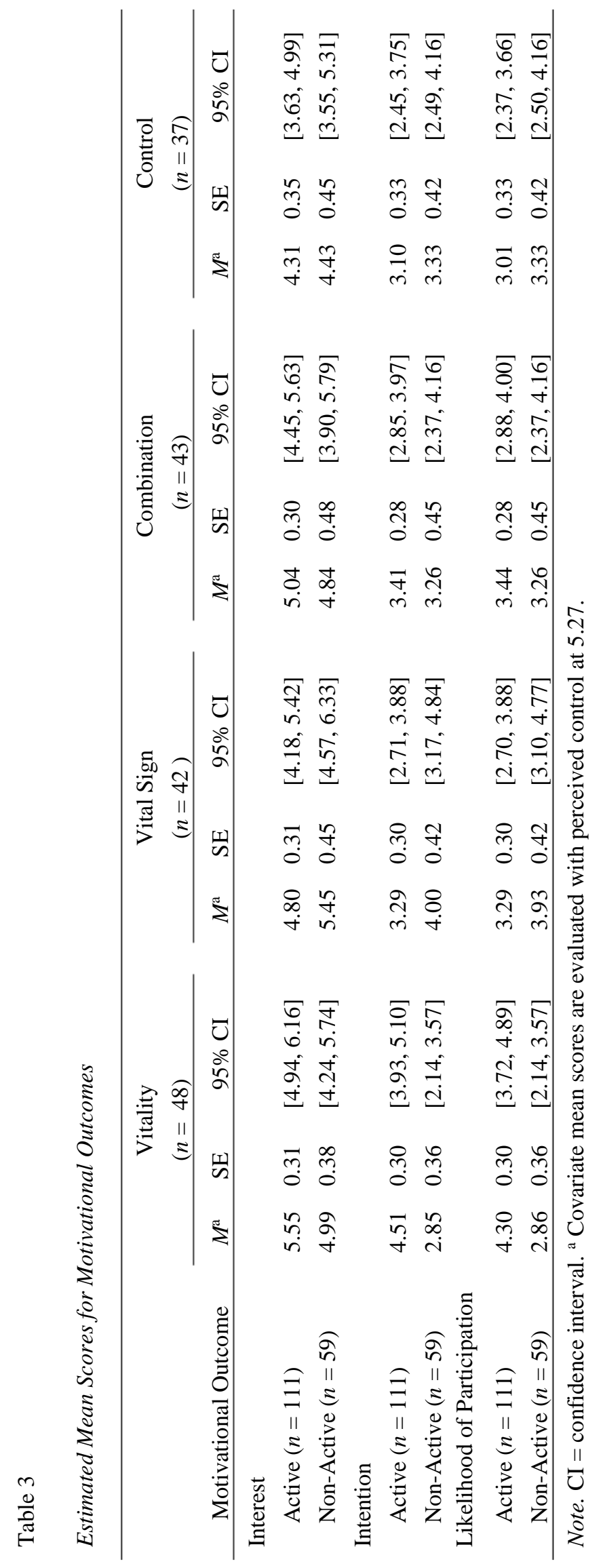


Figure 1. Flyer Message by Condition

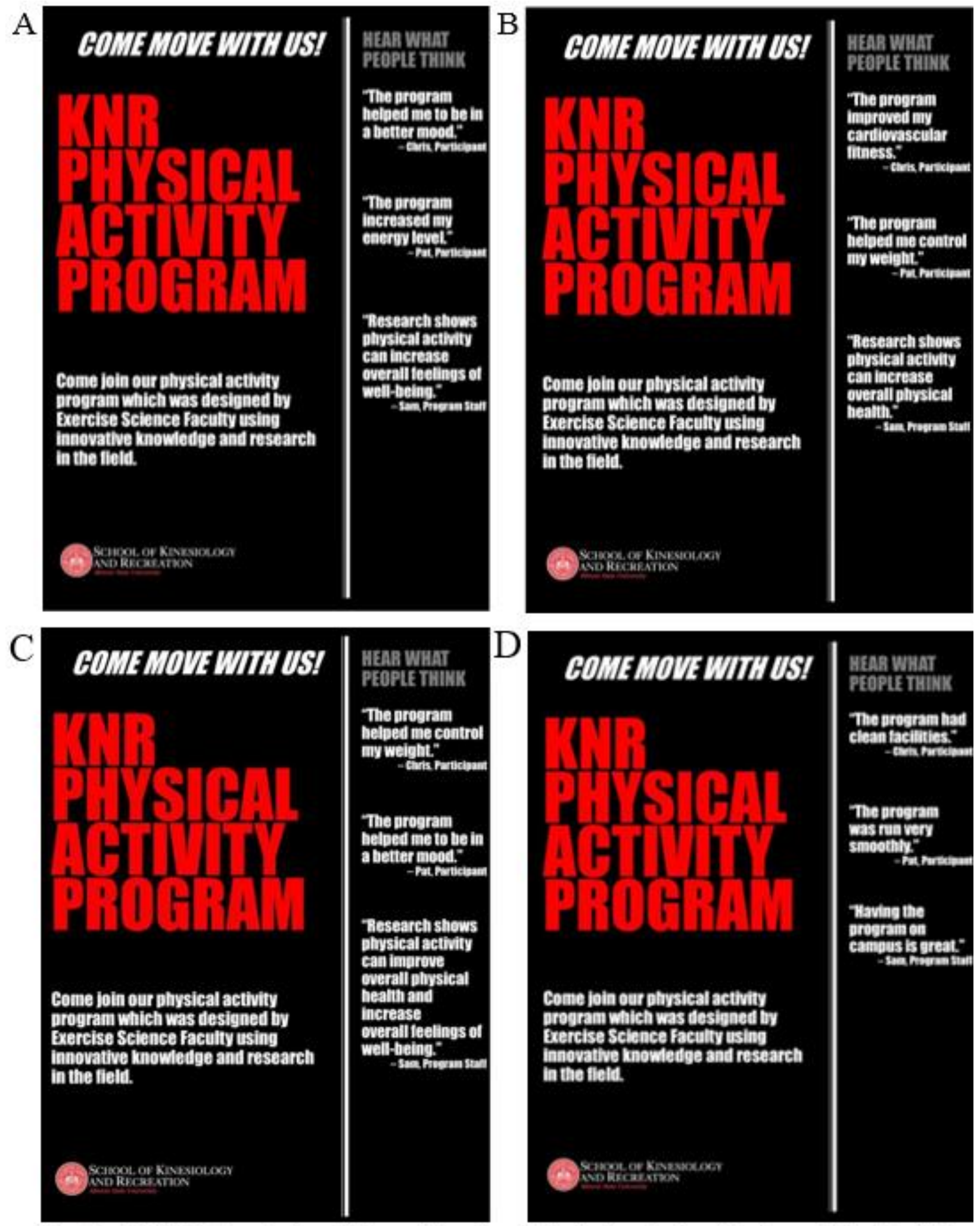

Note. Panel A is the flyer for the vitality condition; Panel B is the flyer for the vital sign condition; Panel C is the flyer for the combination condition; Panel D is the flyer for the control condition 
Figure 2. Interest in the Physical Activity Program ANCOVA Results

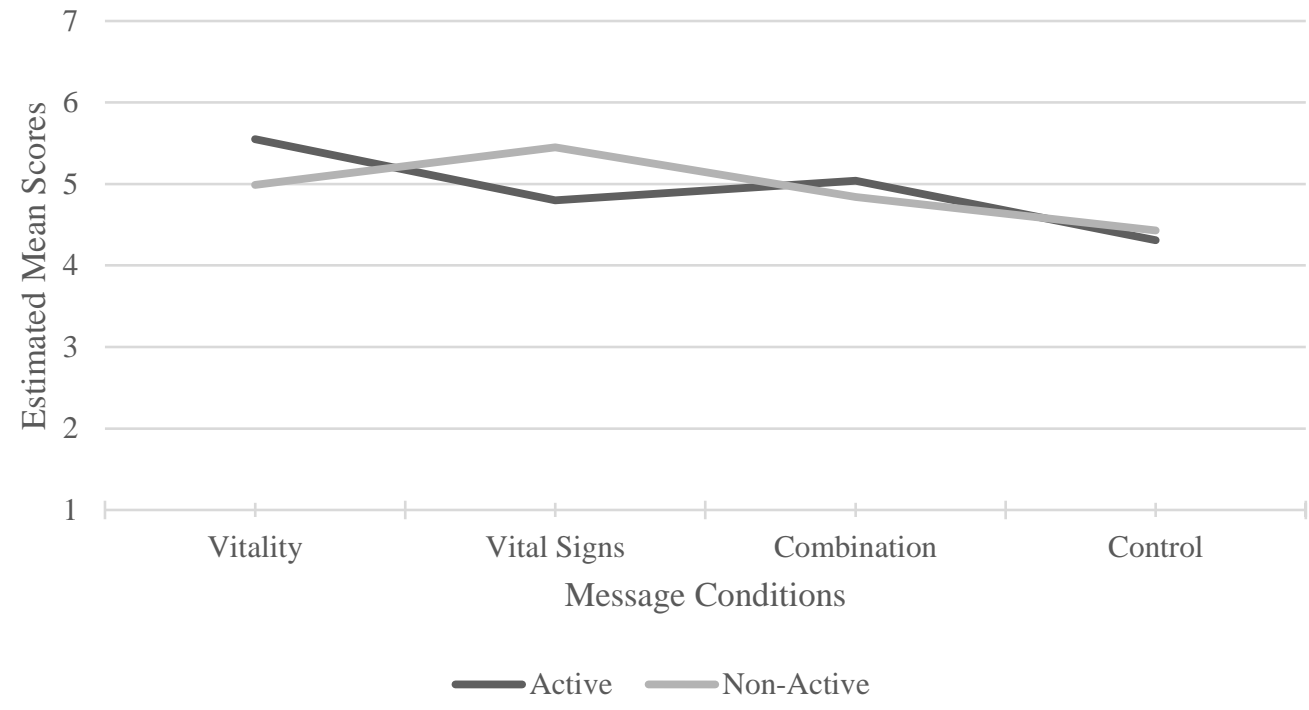

Figure 3. Intention to Participate ANCOVA Results

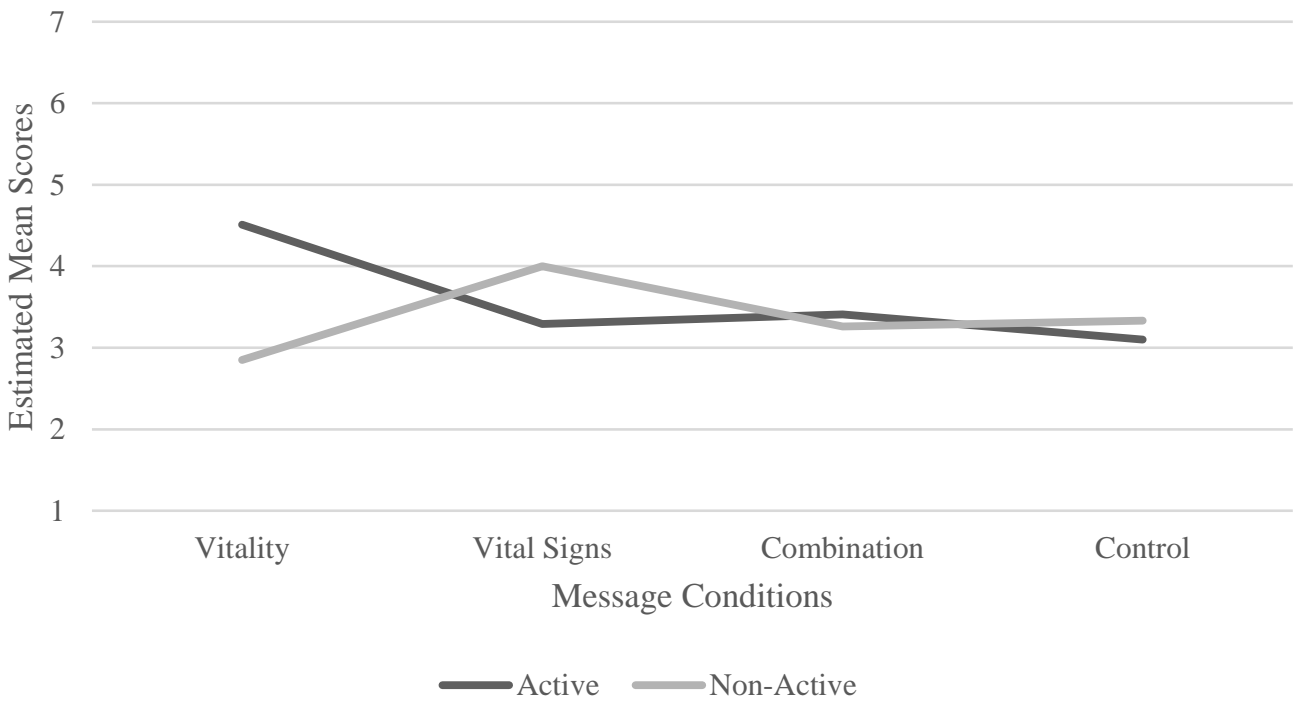


Figure 4. Likelihood of Participation ANCOVA Results

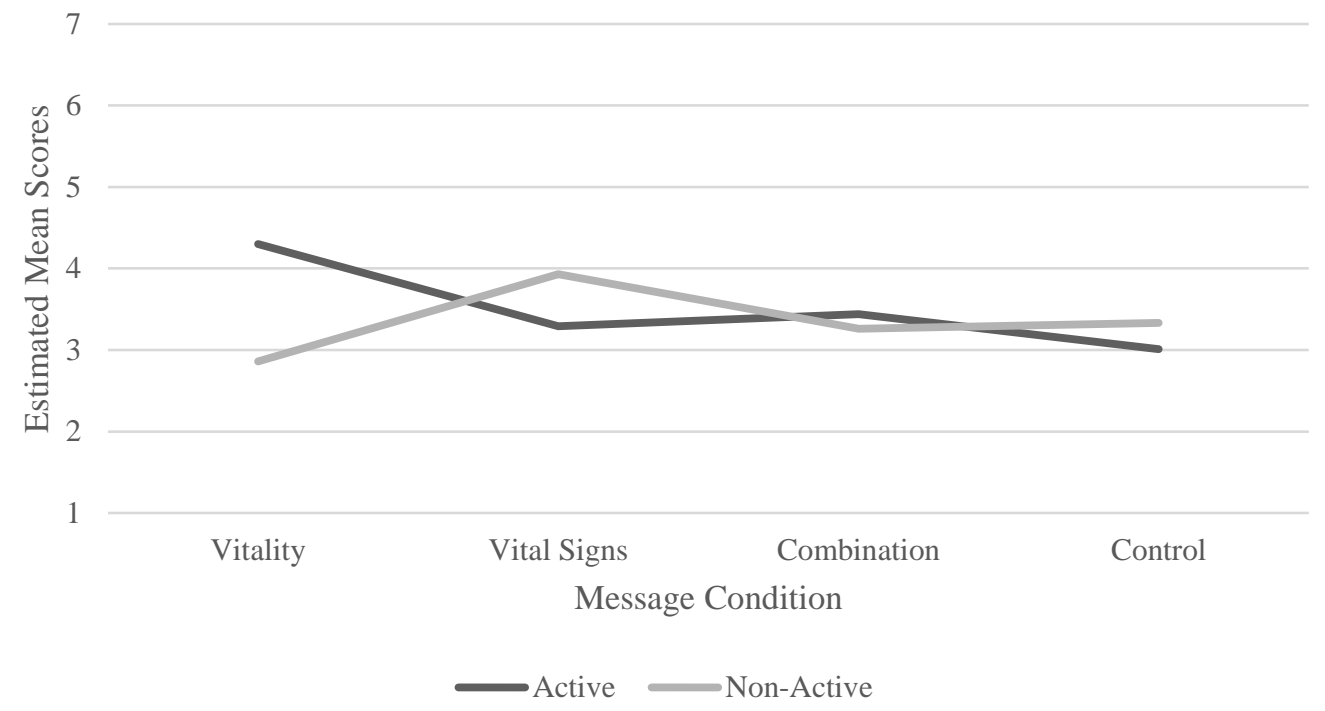

Figure 5. Chi-Squared Analysis for Participants Indicating "Yes" to Sign-Up for the Program

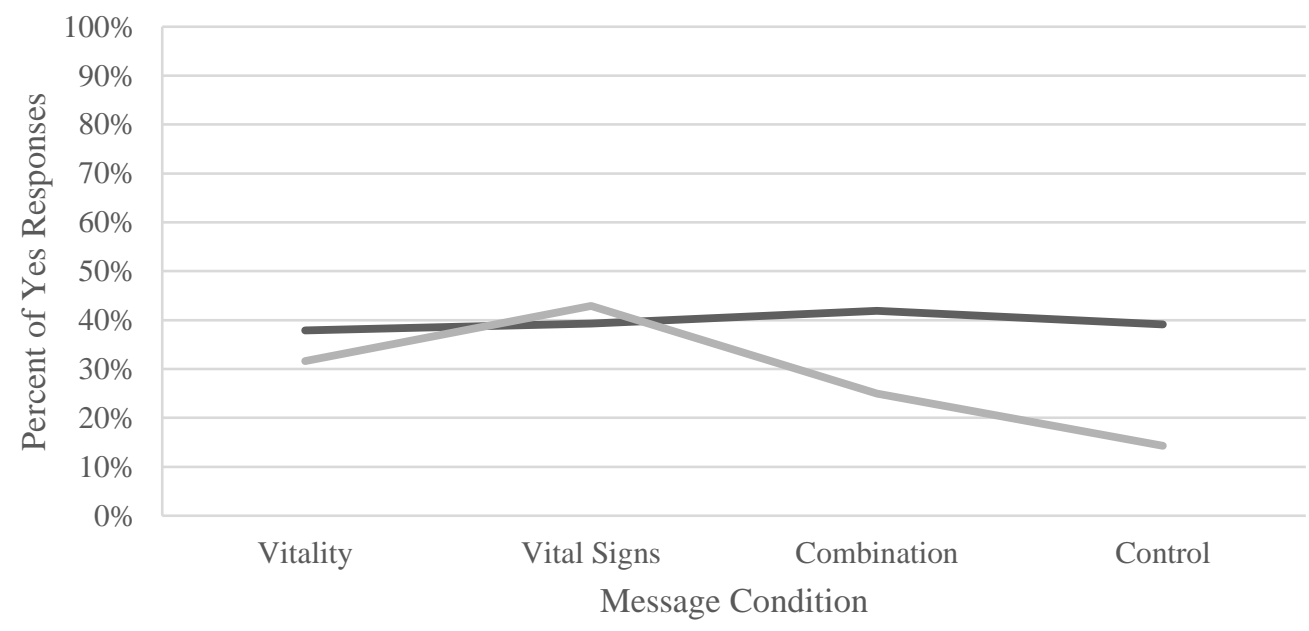

$\longrightarrow$ Active $\longrightarrow$ Non-Active 


\section{References}

Arora, R., Stoner, C., \& Arora, A. (2006). Using framing and credibility to incorporate exercise and fitness in individuals' lifestyle. Journal of Consumer Marketing, 23(4), 199-207.

Berry, T. R., \& Carson, V. (2010). Ease of imagination, message framing, and physical activity messages. British Journal of Health Psychology, 15(1), 197-211.

doi:10.1348/135910709X447811

Blair, S. N., Haskell, W. L., Ho, P., Paffenbarger, R. S., Jr., Vranizan, K. M., Farquhar, J. W., Wood, P. D. (1985). Assessment of habitual physical activity by a seven-day recall in a community survey and controlled experiments. American Journal of Epidemiology, 122(5), 794-804.

Brand, R., \& Ekkekakis, P. (2017). Affective-reflective theory of physical inactivity and exercise: foundations and preliminary evidence. German Journal of Exercise \& Sport Research, 48(1), 48-58. doi:10.1007/s12662-017-0477-9

Craig, C. L., Marshall, A. L., Sjorstrom, M., Bauman, A. E., Booth, M. L., Ainsworth, B. E., ... Oja, P. (2003) International physical activity questionnaire: 12-country reliability and validity. Medicine and Science in Sports and Exercise, 35(8), 1381-1395.

doi:10.1249/01.MSS.0000078924.61453.FB

Conner, M., Rhodes, R. E., Morris, B., McEachan, R., \& Lawton, R. (2011). Changing exercise through targeting affective or cognitive attitudes. Psychology \& Health, 26(2), 133-149. doi:10.1080/08870446.2011.531570

Covey, J. (2014). The role of dispositional factors in moderating message framing effects. Health Psychology, 33(1). 52-65. 
de Bruijn, G., Out, K., \& Rhodes, R. E. (2014). Testing the effects of message framing, kernel state, and exercise guideline adherence on exercise intentions and resolve. British Journal of Health Psychology, 19(4), 871-885. doi:10.1111/bjhp.12086

Dunton, G. F., \& Vaughan, E. (2008). Anticipated affective consequences of physical activity adoption and maintenance. Health Psychology, 27(6), 703-710. doi:10.1037/02786133.27.6.703

Ekkekakis, P. (2013). The measurement of affect, mood, and emotion. New York: Cambridge University Press.

Ekkekakis, P., \& Petruzzello, S. J. (2000). Analysis of the affect measurement conundrum in exercise psychology. I. Fundamental issues. Psychology of Sport \& Exercise, 1, 71-88. doi:10.1016/S1469-0292(00)00010-8

Exercise: Stages of Change (Short Form). (n.d.). Retrieved March 14, 2018, from https://web.uri.edu/cprc/exercise-stages-of-change-short-form/

Facts about Physical Activity. (2014, May 23). Retrieved December 12, 2017, from https://www.cdc.gov/physicalactivity/data/facts.htm

Gellert, P., Ziegelmann, J. P., \& Schwarzer, R. (2012). Affective and health-related outcome expectancies for physical activity in older adults. Psychology \& Health, 27(7), 816-828. doi:10.1080/08870446.2011.607236

Godin, G., \& Shepard, R. J., (1985). A simple method to assess exercise behavior in the community. Canadian Journal of Applied Sport Science, 10, 141-146.

Helfer, S. G., Elhai, J. D., \& Geers, A. L. (2015). Affect and exercise: positive affective expectations can increase post-exercise mood and exercise intentions. Annals of Behavioral Medicine, 49(2), 269-279. 
Humphreys, B. R., McLeod, L., \& Ruseski, J. E. (2014). Physical activity and health outcomes: evidence from Canada. Health Economics, 23(1), 33-54.

Jones, L. W., Sinclair, R. C., \& Courneya, K. S. (2003). The effects of source credibility and message framing on exercise intentions, behaviors, and attitudes: an integration of the elaboration likelihood model and prospect theory. Journal of Applied Social Psychology, 33(1), 179-196.

Kin-Kit, L., Sheung-Tak, C., \& Fung, H. H. (2014). Effects of message framing on self-report and accelerometer-assessed physical activity across age and gender groups. Journal of Sport \& Exercise Psychology, 36(1), 40-51. doi:10.1123/jsep.2012-0278

Kiviniemi, M. T., Voss-Humke, A. M., \& Seifert, A. L. (2007). How do I feel about the behavior? The interplay of affective associations with behaviors and cognitive beliefs as influences on physical activity behavior. Health Psychology, 26(2), 152-158.

doi:10.1037/0278-6133.26.2.152

Kwan, B. M. \& Bryan, A. (2010). In-task and post-task affective response to exercise: translating exercise intentions into behaviour. British Journal of Health Psychology, 15, 115-131. doi:10.1348/135910709X433267

Latimer, A. E., Rench, T. A., Rivers, S. E., Katulak, N. A., Materese, S. A., Cadmus, L., ... Salovey, P. (2008). Promoting participation in physical activity using framed messages: An application of prospect theory. British Journal of Health Psychology, 13(4), 659-681. doi:10.1348/135910707X246186

Latimer, A. E., Brawley, L. R., \& Bassett, R. L. (2010). A systematic review of three approaches for constructing physical activity messages: what messages work and what improvements 
are needed? International Journal of Behavioral Nutrition \& Physical Activity, 7(36), 117. doi:10.1186/1479-5868-7-36

Lawton, R., Conner, M., \& McEachan, R. (2009). Desire or reason: predicting health behaviors from affective and cognitive Attitudes. Health Psychology, 28(1), 56-65.

Lowe, R., Eves, F., \& Carroll, D. (2002). The influence of affective and instrumental beliefs on exercise intentions and behavior: a longitudinal analysis. Journal of Applied Social Psychology, 32(6), 1241-1252.

Morris, B., Lawton, R., McEachan, R., Hurling, R., \& Conner, M. (2016). Changing selfreported physical activity using different types of affectively and cognitively framed health messages, in a student population. Psychology, Health \& Medicine, 21(2), 198207. doi:10.1080/13548506.2014.997762

Parrott, M. W., Tennant, L. K., Olejnik, S., \& Poudevigne, M. S. (2008). Theory of planned behavior: implications for an email-based physical activity intervention. Psychology of Sport \& Exercise, 9, 511-526. doi:10.1016/j.psychsport.2007.07.002

Pfeffer, I. (2013). Regulatory fit messages and physical activity motivation. Journal of Sport \& Exercise Psychology, 35(2), 119-131.

Rejeski, R.W., Best, D., Griffith, P., \& Kenney, E (1987). Sex-role orientation and the responses of men to exercise stress. Research Quarterly for Exercise and Sport, 58, 260-264.

Rhodes, R. E., \& Courneya, K. S. (2005). Threshold assessment of attitude, subjective norm, and perceived behavioral control for predicting exercise intention and behavior. Psychology of Sport \& Exercise, 6, 349-361. doi:10.1016/j.psychsport.2004.04.002

Rothman, A. J., \& Salovey, P. (1997). Shaping perceptions to motivate healthy behavior: the role of message framing. Psychological Bulletin, 121(1), 3-19. 
Rothman, A. J., Wlaschin, J. T., Bartels, R. D., Latimer, A., \& Salovey, P. (2008). How persons and situations regulate message framing effects: the study of health behavior. In A. J. Elliot (Eds.), Handbook of approach and avoidance motivation (pp. 475-486). New York, NY: Psychology Press.

Ryan, R. M., \& Deci, E. L. (2017). Self-determination theory: Basic psychological needs in motivation, development, and wellness. New York, NY, US: Guilford Press.

Sallis, R. (2015). Exercise is medicine: a call to action for physicians to assess and prescribe exercise. Physician \& Sports Medicine 43(1), 22-26.

doi:10.1080/00913847.2015.1001938.

Sallis, J.F., Haskell, W. L., Wood, P. D., Fortmann, S. P., Rogers, T., Blair, S.N., Paffenbarger, R. S., Jr. (1985). Physical activity assessment methodology in the Five-City Project. American Journal of Epidemiology, 121(1), 91-106.

Segar, M. L., Guérin, E., Phillips, E., \& Fortier, M. (2016). From a vital sign to vitality: selling exercise so patients want to buy it. Current Sports Medicine Reports (Lippincott Williams \& Wilkins), 15(4), 276-281. doi:10.1249/JSR.0000000000000284

Sirriyeh, R., Lawton, R., \& Ward, J. (2015). Physical activity and adolescents: an exploratory randomized controlled trial investigating the influence of affective and instrumental text messages': Erratum. British Journal of Health Psychology, 20(2), 447-448. doi:10.1111/bjhp.12140

U.S. Department of Health and Human Services. (2000). Healthy people 2020: Understanding and improving health (2nd ed.). Washington, DC: U.S. Government Printing Office. 
Updegraff, J. A., \& Rothman, A. J. (2013). Health message framing: moderators, mediators, and mysteries. Social \& Personality Psychology Compass, 7(9), 668-679. doi:10.1111/spc3.12056

van 't Riet, J., Ruiter, R. A., Werrij, M. Q., \& de Vries, H. (2010). Investigating message-framing effects in the context of a tailored intervention promoting physical activity. Health Education Research, (2), 343-354.

Williams, D. M. (2008). Exercise, affect, and adherence: an integrated model and a case for selfpaced exercise. Journal of Sport \& Exercise Psychology, 30(5), 471-496.

Williams, D. M., Dunsiger, S., Ciccolo, J. T., Lewis, B. A., Albrecht, A. E., \& Marcus, B. H. (2008). Acute affective response to a moderate-intensity exercise stimulus predicts physical activity participation 6 and 12 months later. Psychology of Sport \& Exercise, 9, 231-245. doi:10.1016/j.psychsport.2007.04.002

Zhang, Y., Fishbach, A., \& Kruglanski, A. W. (2007). The dilution model: how additional goals undermine the perceived instrumentality of a shared path. Journal of Personality and Social Psychology, 92(3), 389-401. doi:10.1037/0022-3514.92.3.389 


\section{APPENDIX A: PHYSICAL ACTIVITY PROMOTION SURVEY}

\section{Physical Activity Promotion}

Thank you for considering participating in our research study on physical activity. Our main goal is to understand how faculty, staff and students at Illinois State University think and feel about physical activity. We are also interested in gauging interest in a physical activity program designed by faculty in the School of Kinesiology and Recreation here at Illinois State University. Your participation in this study is voluntary. There are no penalties for choosing not to participate. Further, you may withdraw at any time, for any reason, without penalty. Completing the survey will take approximately 10-15 minutes. There are minimal foreseeable risks involved in completing the survey. You could possibly feel some discomfort and/or self-conscious about answering questions about yourself and/or your physical activity behavior. Please note, however, that there are no correct or incorrect answers to any of the questions on the survey, and you may skip any question you prefer not to answer. Further, all responses will be completely anonymous. Although there are no direct benefits to you, your participation in this study may help to identify ways promote physical activity participation. Only those 18 years or older are permitted to participate.

If you have any questions or concerns about this study please contact the principal investigator,

Dr. Anthony Amorose at (309) ***_****. If you have questions about participant research rights and/or want to report a research related injury or adverse effect, please contact the Research Ethics and Compliance office at Illinois State University at (309) 438-2529 and/or rec@ilstu.edu. By clicking on the "next" button and answering the survey questions you are providing 


\section{your consent to participate in the anonymous research study. If you chose not to consent}

\section{then you can simply close the survey web page. Thanks in advance for your consideration.}

Thank you for agreeing to complete the survey. Please answer the following questions.

Remember, there are no right or wrong answers. We are simply interested in your feelings about physical activity and about your perceptions of a physical activity program designed by faculty in the School of Kinesiology and Recreation here at Illinois State University.

How old are you (years)?

What is your gender?

Male

Female

Transgender

Other

Prefer not to say

Please indicate your race/ethnicity.

White

Black or African American

American Indian or Alaska Native

Asian

Native Hawaiian or Pacific Islander

Other 
Are you currently a KNR student or have you previously earned a degree in kinesiology, exercise science, or a related field?

Yes

No

We are interested in finding out about the kinds of physical activities that people do as part of their everyday lives. The questions are about the time you spent being physically active in the last 7 days. They include questions about activities you do at work, as part of your house and yard work, to get from place to place, and in your spare time for recreation, exercise or sport. Your answers are important. Please answer each question even if you do not consider yourself to be an active person in answering the following questions,

"Vigorous" physical activities refer to activities that take hard physical effort and make you breathe much harder than normal.

"Moderate" activities refer to activities that take moderate physical effort and make you breathe somewhat harder than normal.

During the last 7 days, on how many days did you do vigorous physical activities like heavy lifting, digging, aerobics, or fast bicycling? Think about only those physical activities that you did for at least 10 minutes at a time.

\begin{tabular}{c|cccccccc} 
& 0 & 1 & 2 & 3 & 4 & 5 & 6 & 7 \\
\hline $\begin{array}{c}\text { How } \\
\text { many } \\
\text { days per } \\
\text { week? }\end{array}$ & & & & & & & & \\
\end{tabular}


How much time in total did you usually spend on one of those days doing vigorous physical activities?

Hours

Minutes

Again, think only about those physical activities that you did for at least 10 minutes at a time.

During the last 7 days, on how many days did you do moderate physical activities like carrying light loads, bicycling at a regular pace, or doubles tennis? Do not include walking.

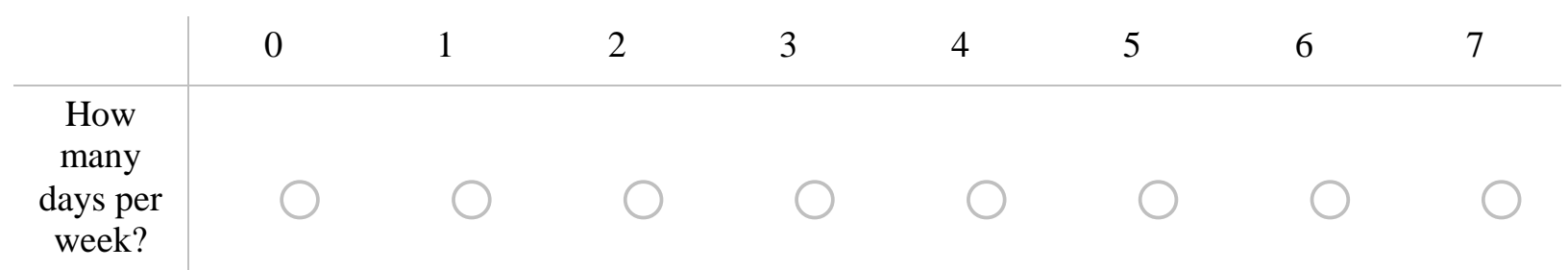

How much time in total did you usually spend on one of those days doing moderate physical activities?

Hours

Minutes

During the last 7 days, on how many days did you walk for at least 10 minutes at a time? This includes walking at work and at home, walking to travel from place to place, and any other walking that you did solely for recreation, sport, exercise or leisure.

\begin{tabular}{c|cccccccc} 
& 0 & 1 & 2 & 3 & 4 & 5 & 6 & 7 \\
\hline $\begin{array}{c}\text { How } \\
\text { many } \\
\text { days per } \\
\text { week? }\end{array}$ & & & & & & & & \\
\end{tabular}

How much time in total did you usually spend walking on one of those days?

Hours

Minutes 
Regular Exercise is any planned physical activity (e.g., brisk walking, aerobics, jogging, bicycling, swimming, rowing, etc.) performed to increase physical fitness. Such activity should be performed 3 to 5 times per week for 20-60 minutes per session. Exercise does not have to be painful to be effective but should be done at a level that increases your breathing rate and causes you to break a sweat.

Yes. I have been for MORE than 6 months.

Yes. I have been for LESS than 6 months.

No, but I intend to in the next 30 days.

No, but I intend to in the next 6 months.

No, and I do NOT intend to in the next 6 months.

The following set of questions ask about your views on physical activity participation. For me, participating in physical activity is...

\begin{tabular}{|c|c|c|c|c|c|c|c|c|}
\hline useful & 0 & 0 & 0 & 0 & 0 & 0 & 0 & useless \\
\hline enjoyable & 0 & $\bigcirc$ & $\bigcirc$ & 0 & $\bigcirc$ & $\bigcirc$ & $\bigcirc$ & unenjoyable \\
\hline wise & $\bigcirc$ & 0 & $\bigcirc$ & 0 & 0 & $\bigcirc$ & 0 & foolish \\
\hline interesting & 0 & 0 & $\bigcirc$ & 0 & 0 & 0 & $\bigcirc$ & boring \\
\hline beneficial & $\bigcirc$ & 0 & $\bigcirc$ & 0 & 0 & $\bigcirc$ & 0 & harmful \\
\hline relaxing & 0 & $\bigcirc$ & 0 & 0 & $\bigcirc$ & 0 & $\bigcirc$ & stressful \\
\hline
\end{tabular}


On the next page you will find a flyer we use to promote a physical activity program on campus. We are interested in gauging interest in the KNR PHYSICAL ACTIVITY PROGRAM mentioned in the flyer.

Please read the promotional flyer carefully. After reading it, we will ask you some questions about the content of the message and about your thoughts about the program.

The following set of questions asks you to reflect on the promotional flyer about the KNR Physical Activity Program you just read. Please indicate the truthfulness of following statements.

Based on the information contained in the promotional flyer, the KNR physical activity program... 


\begin{tabular}{|c|c|c|c|c|c|c|}
\hline & $\begin{array}{l}\text { Definitely } \\
\text { true }\end{array}$ & $\begin{array}{l}\text { Probably } \\
\text { true }\end{array}$ & $\begin{array}{l}\text { Neither } \\
\text { true nor } \\
\text { false }\end{array}$ & $\begin{array}{l}\text { Probably } \\
\text { false }\end{array}$ & $\begin{array}{l}\text { Definitely } \\
\text { false }\end{array}$ & $\begin{array}{l}\text { Unsure/Do } \\
\text { not Know }\end{array}$ \\
\hline $\begin{array}{l}\text { is based on innovative } \\
\text { research. }\end{array}$ & & & & & & \\
\hline $\begin{array}{l}\text { is only available to } \\
\text { current ISU students. } \\
\text { is only available to } \\
\text { people who do not } \\
\text { currently exercise. }\end{array}$ & & & & & & 0 \\
\hline $\begin{array}{l}\text { was designed by KNR } \\
\text { faculty. }\end{array}$ & & & & & & \\
\hline $\begin{array}{l}\text { led to } \\
\text { psychological/emotional } \\
\text { benefits for former } \\
\text { participants (e.g., better } \\
\text { mood, increased } \\
\text { energy). }\end{array}$ & & & & & & \\
\hline $\begin{array}{l}\text { led to physical health } \\
\text { benefits for former } \\
\text { participants (e.g., } \\
\text { controlled weight, } \\
\text { increased } \\
\text { cardiovascular fitness). }\end{array}$ & & & & & & \\
\hline $\begin{array}{l}\text { lead to psychological } \\
\text { AND physical health } \\
\text { benefits for former } \\
\text { participants. }\end{array}$ & & & & & & \\
\hline $\begin{array}{l}\text { occurs in a newly } \\
\text { updated facility. }\end{array}$ & & & & & & \\
\hline
\end{tabular}


This set of questions also asks you to reflect on the promotional flyer about the KNR Physical Activity Program. Please rate the information included in the message using the following descriptors.

The information contained in the promotional flyer about the KNR Physical Activity Program was....

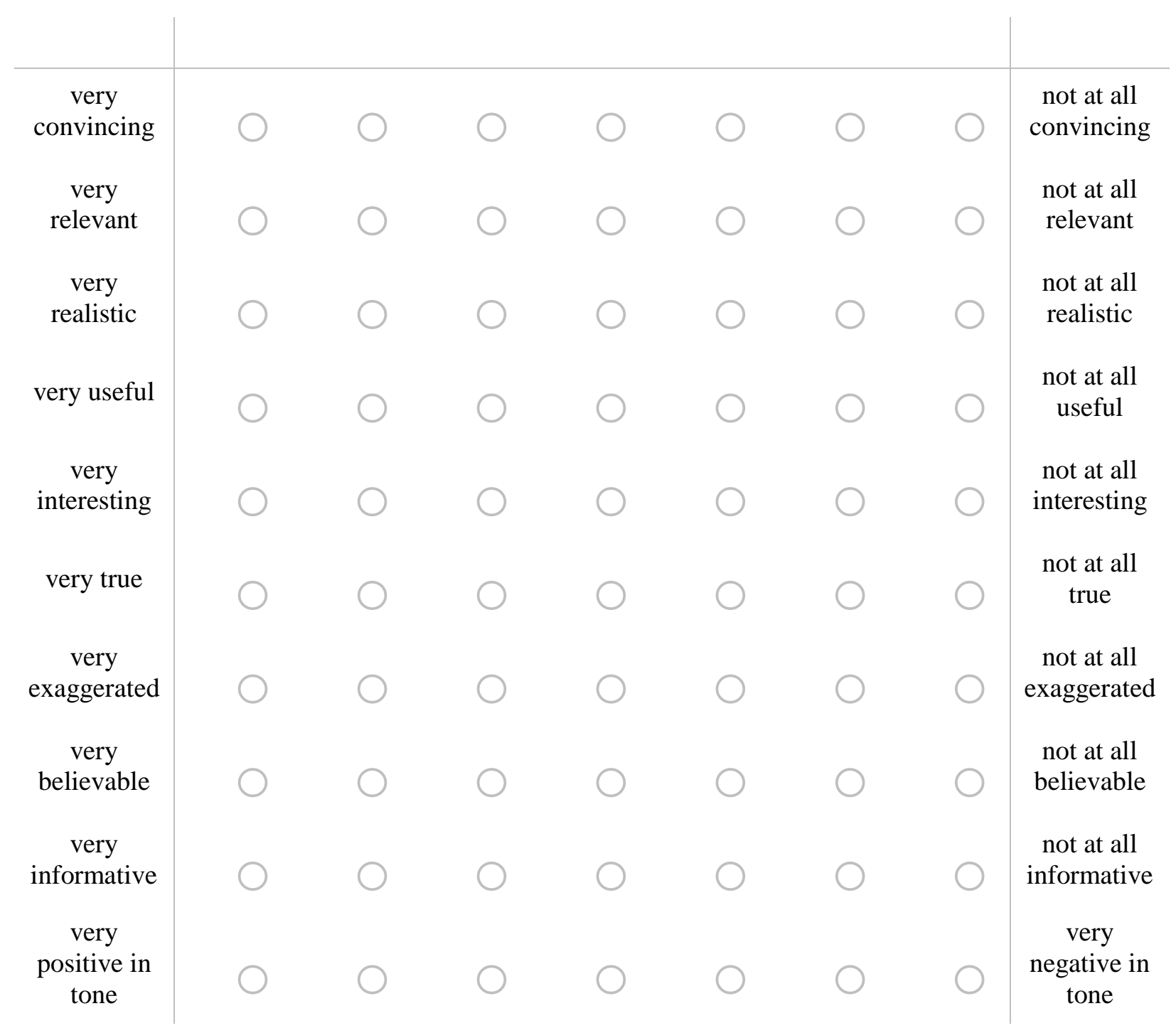


The following set of questions ask about your PERSONAL views on the KNR physical activity program.

For me, participating in the KNR physical activity program would be...

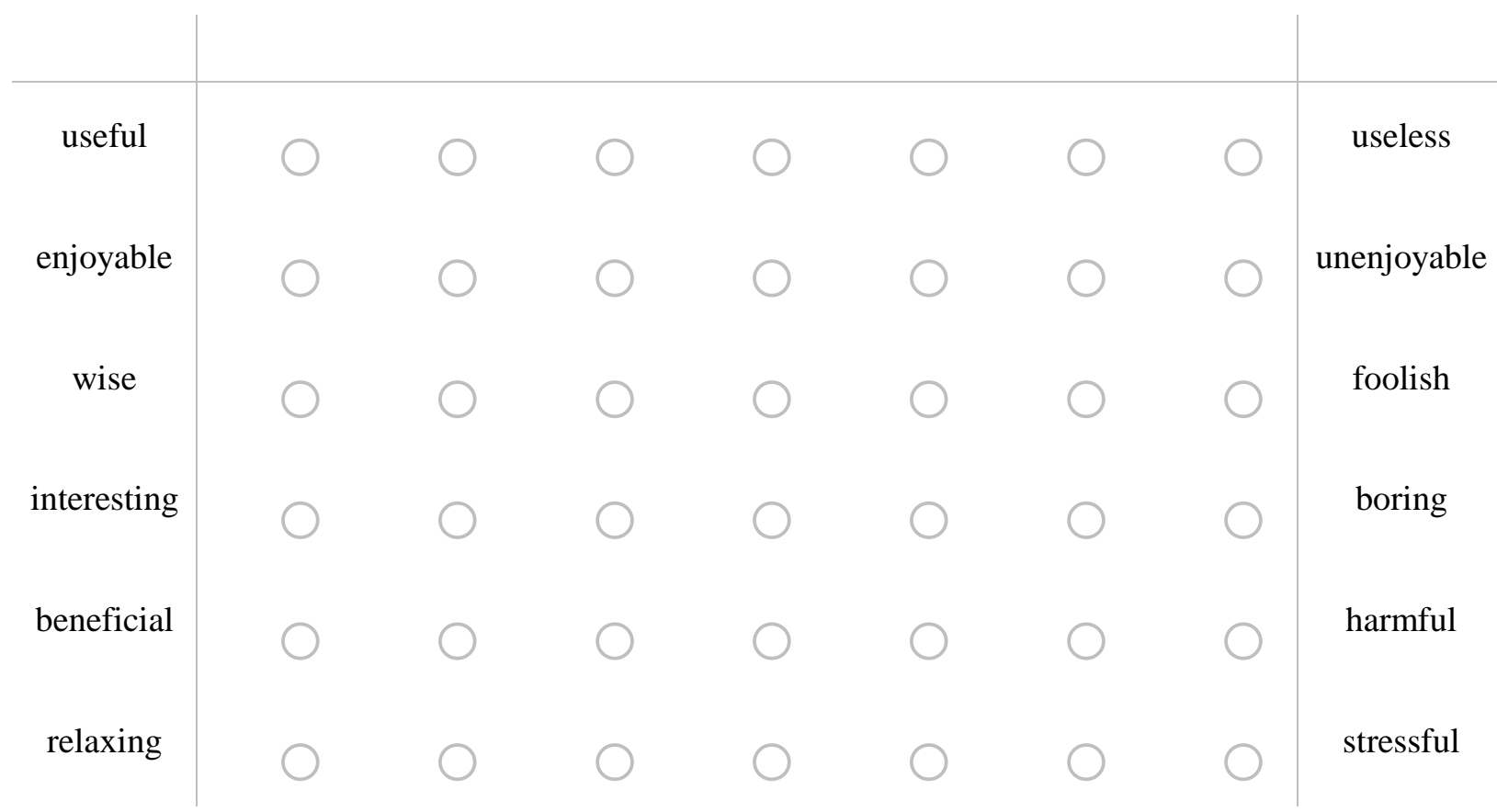

How confident are you that you could participate in the KNR physical activity program if you wanted to do so?

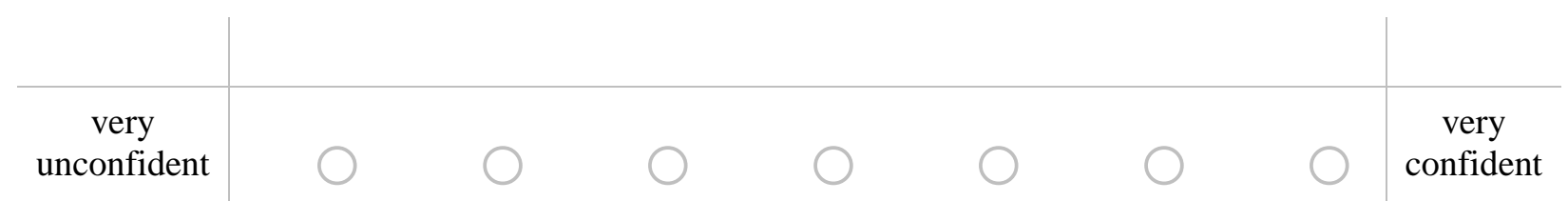

How much personal control do you feel you have over participating in the KNR physical activity program?

\begin{tabular}{c|ccccccc|c}
\hline $\begin{array}{c}\text { very } \\
\text { little } \\
\text { control }\end{array} \quad \bigcirc$ & & & & & & \\
\hline
\end{tabular}


Participating in the KNR physical activity program is completely up to me.

\begin{tabular}{l|lllll|l} 
strongly \\
disagree
\end{tabular}$\quad \begin{array}{lllll}\text { strongly } \\
\text { agree }\end{array}$

If I wanted to, I have the physical ability to participate in the KNR physical activity program.

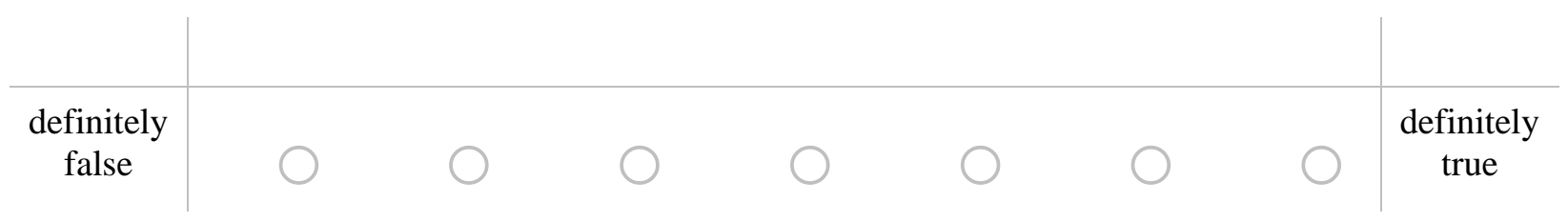

If I wanted to, I have the ability to find time in my schedule to participate in the KNR physical activity program.

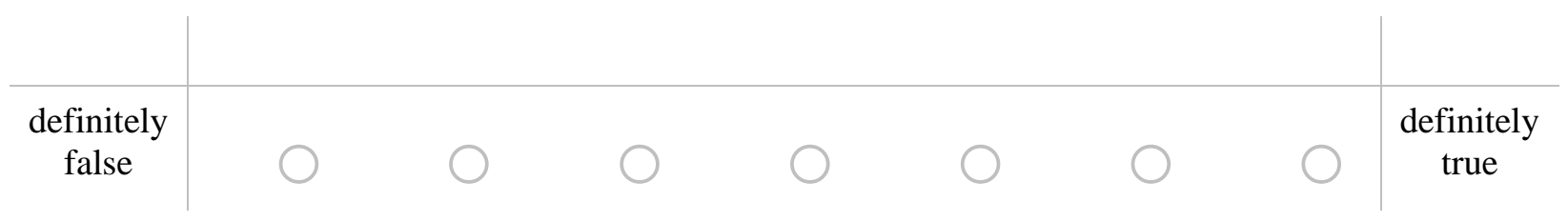

If I wanted to, I have the energy to participate in the KNR physical activity program.

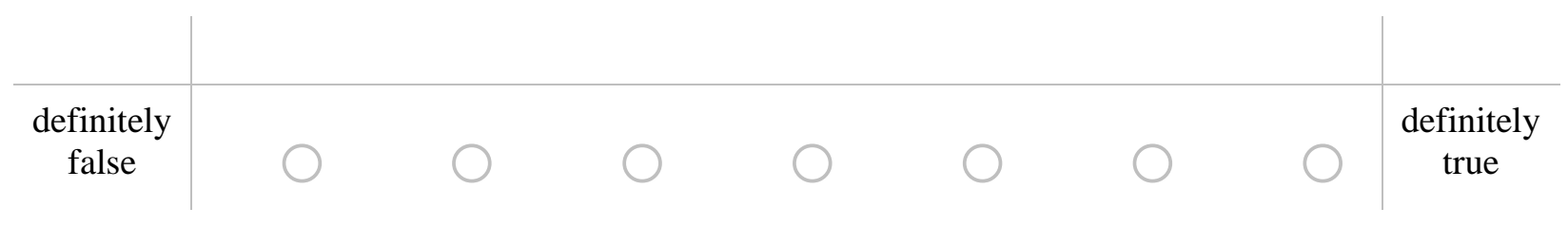


If you participated in the KNR physical activity program, how likely do you think the following would happen?

If I participated in the KNR physical activity program, it would...

\begin{tabular}{|c|c|c|c|c|c|c|c|}
\hline & $\begin{array}{c}\text { not at all } \\
\text { likely }\end{array}$ & & & & & & $\begin{array}{c}\text { extremely } \\
\text { likely }\end{array}$ \\
\hline $\begin{array}{l}\text { help me to be } \\
\text { in a better } \\
\text { mood }\end{array}$ & 0 & 0 & 0 & 0 & $\bigcirc$ & 0 & 0 \\
\hline $\begin{array}{l}\text { improve my } \\
\text { cardiovascular } \\
\text { fitness }\end{array}$ & 0 & 0 & 0 & 0 & 0 & 0 & $\bigcirc$ \\
\hline $\begin{array}{l}\text { increase my } \\
\text { energy level }\end{array}$ & 0 & 0 & 0 & 0 & 0 & 0 & 0 \\
\hline $\begin{array}{l}\text { help me } \\
\text { control my } \\
\text { weight }\end{array}$ & 0 & 0 & 0 & 0 & $\bigcirc$ & 0 & 0 \\
\hline $\begin{array}{l}\text { increase my } \\
\text { overall feeling } \\
\text { of well-being }\end{array}$ & 0 & 0 & 0 & 0 & 0 & 0 & $\bigcirc$ \\
\hline $\begin{array}{l}\text { improve my } \\
\text { overall } \\
\text { physical } \\
\text { health }\end{array}$ & 0 & 0 & 0 & 0 & $\bigcirc$ & 0 & 0 \\
\hline
\end{tabular}


If you participated in the KNR physical activity program, how valuable would the following potential benefits be to you?

\begin{tabular}{c|c|ccc}
$\begin{array}{c}\text { of little } \\
\text { value }\end{array}$ \\
$\begin{array}{c}\text { helping me to } \\
\text { be in a better } \\
\text { mood }\end{array}$ & & & &
\end{tabular}

Please answer the following questions about your interest in the KNR physical activity

program.

How interested are you in learning more about the KNR physical activity program?

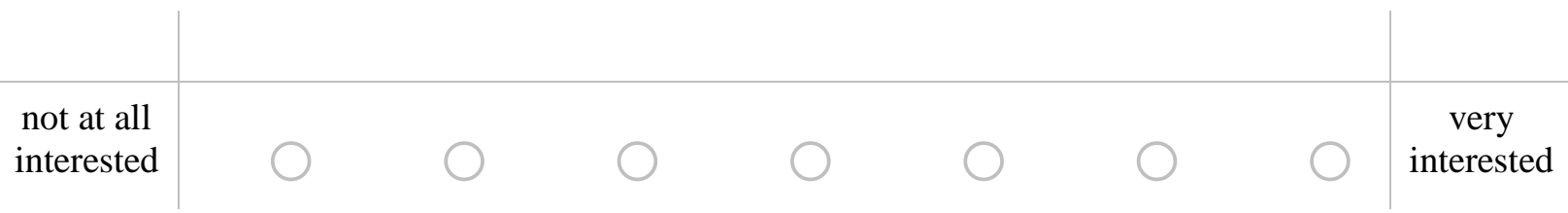


Do you intend on signing up for the KNR physical activity program this school year?

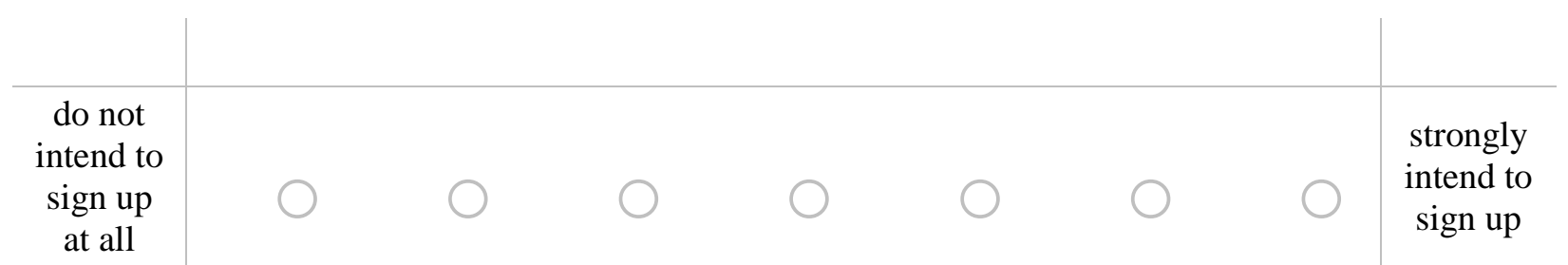

How likely is it that you will participate in the KNR physical activity program this school year?

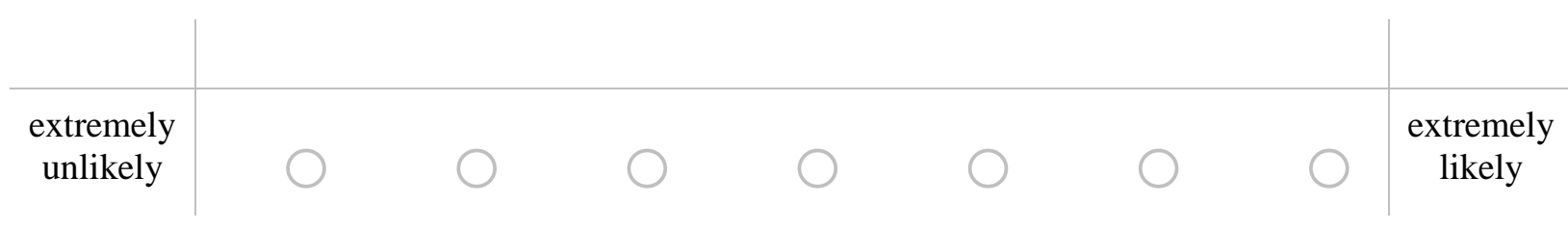

If you would like to go ahead and schedule an initial session in the KNR physical activity

program, click the option labelled "Yes". If not, please click "No".

Yes - I would like to sign up for an initial session (clicking this link will allow you to access the KNR physical activity program scheduling calendar at the conclusion of the survey)

No - I am not interested in scheduling a session.

Thank you for participating in our survey.

The KNR physical activity program mentioned in the promotional flyer is fictitious. No program housed in the School of KNR currently exists. It was necessary for us to use this minor deception as a way to test if people would be more or less likely to want to participate in a physical activity program after receiving different versions of the promotional flyer. The flyers differed on the types of benefits one may receive by engaging in a physical activity program (e.g., physical health benefits vs. psychological well-being benefits).

Now that you have knowledge of the actual study purpose, we would like to ask if you are willing to allow us to use your answers to the survey questions as part of our study. Your responses will 
help us to better understand how to effectively promote physical activity. Please indicate your consent to remain a part of the study by answer the question below.

Yes - I consent to allowing the researchers to use my responses as part of this study.

No - I do not consent to the researchers using my response as part of this study.

If you have any questions or concerns about this study please contact the principal investigator, Dr. Anthony Amorose at (309) $* * *_{-} * * * *$. If you have questions about participant research rights and/or want to report a research related injury or adverse effect, please contact the Research Ethics and Compliance office at Illinois State University at (309) 438-2529 and/or rec@ilstu.edu. 